OPEN ACCESS

Edited by:

Jing Zhou,

Peking University, China

Reviewed by:

James Pritchett,

Manchester Metropolitan University,

United Kingdom

Weijuan Yao,

Peking University Health Science

Centre, China

*Correspondence:

Thomas Braun

Thomas.Braun@mpi-bn.mpg.de

${ }^{\dagger}$ These authors have contributed equally to this work

Specialty section: This article was submitted to

Molecular Medicine,

a section of the journal

Frontiers in Cell and Developmental

Biology

Received: 08 December 2020 Accepted: 19 April 2021 Published: 26 May 2021

Citation:

lanni A, Hofmann M, Kumari $P$,

Tarighi S, Al-Tamari HM, Görgens A, Giebel B, Nolte H, Krüger M, Salwig I,

Pullamsetti SS, Günther A,

Schneider $A$ and Braun T (2021)

Depletion of Numb and Numblike

in Murine Lung Epithelial Cells

Ameliorates Bleomycin-Induced Lung

Fibrosis by Inhibiting the $\beta$-Catenin

Signaling Pathway.

Front. Cell Dev. Biol. 9:639162.

doi: 10.3389/fcell.2021.639162

\section{Depletion of Numb and Numblike in Murine Lung Epithelial Cells Ameliorates Bleomycin-Induced Lung Fibrosis by Inhibiting the $\beta$-Catenin Signaling Pathway}

\begin{abstract}
Alessandro lanni't, Michael Hofmann ${ }^{1 \dagger}$, Poonam Kumari', Shahriar Tarighi ${ }^{1}$, Hamza M Al-Tamari², André Görgens ${ }^{3}$, Bernd Giebel ${ }^{3}$, Hendrik Nolte ${ }^{4}$, Marcus Krüger ${ }^{4}$, Isabelle Salwig ${ }^{1,5}$, Soni Savai Pullamsetti2,5, Andreas Günther ${ }^{5,6}$, André Schneider ${ }^{1}$ and Thomas Braun ${ }^{1,5 *}$

1 Department of Cardiac Development and Remodeling, Max-Planck-Institute for Heart and Lung Research, Bad Nauheim Germany, ${ }^{2}$ Department of Lung Development and Remodeling, Max-Planck-Institute for Heart and Lung Research, Bad Nauheim, Germany, ${ }^{3}$ Institute for Transfusion Medicine, University Hospital Essen, Essen, Germany, ${ }^{4}$ Cologne Excellence Cluster on Cellular Stress Responses in Aging-Associated Diseases (CECAD)-Cluster of Excellence, Köln, Germany, ${ }^{5}$ Member of the German Center for Lung Research (DZL), Member of the Cardio-Pulmonary Institute (CPI), Bad Nauheim, Germany, ${ }^{6}$ Universities of Giessen and Marburg Lung Center (UGMLC), Justus-Liebig-University, Giessen, Germany
\end{abstract}

Idiopathic pulmonary fibrosis (IPF) represents the most aggressive form of pulmonary fibrosis (PF) and is a highly debilitating disorder with a poorly understood etiology. The lung epithelium seems to play a critical role in the initiation and progression of the disease. A repeated injury of lung epithelial cells prompts type II alveolar cells to secrete pro-fibrotic cytokines, which induces differentiation of resident mesenchymal stem cells into myofibroblasts, thus promoting aberrant deposition of extracellular matrix (ECM) and formation of fibrotic lesions. Reactivation of developmental pathways such as the Wnt- $\beta$-catenin signaling cascade in lung epithelial cells plays a critical role in this process, but the underlying mechanisms are still enigmatic. Here, we demonstrate that the membrane-associated protein NUMB is required for pathological activation of $\beta$-catenin signaling in lung epithelial cells following bleomycin-induced injury. Importantly, depletion of Numb and Numblike reduces accumulation of fibrotic lesions, preserves lung functions, and increases survival rates after bleomycin treatment of mice. Mechanistically, we demonstrate that NUMB interacts with casein kinase 2 (CK2) and relies on $\mathrm{CK} 2$ to activate $\beta$-catenin signaling. We propose that pharmacological inhibition of NUMB signaling may represent an effective strategy for the development of novel therapeutic approaches against PF.

Keywords: lung, fibrosis, epithelium, NUMB, $\beta$-catenin

\section{INTRODUCTION}

Idiopathic pulmonary fibrosis (IPF) is a progressive lung disorder characterized by increased deposition of extracellular matrix (ECM), which results in pathological changes of lung architecture and deterioration of lung functions, ultimately leading to death (Todd et al., 2012; Raghu et al., 2018). Activation of resident mesenchymal stem cells (MSCs) and subsequent differentiation into ECM-secreting myofibroblasts are assumed to be the principal causes for accumulation of fibrotic 
lesions (Todd et al., 2012; Camelo et al., 2014). Numerous studies indicated a critical role of lung epithelial cells, in particular alveolar epithelial cells (AECs), for the initiation and progression of IPF (reviewed in Katzen and Beers, 2020). The alveolar epithelium is mainly composed of two types of pneumocytes: AEC type I and type II (ATI and ATII cells, respectively). ATI pneumocytes are large and thin cells that cover $90-95 \%$ of the alveolar surface, mediating gas exchange. In contrast, the cuboidal ATII pneumocytes secrete antimicrobial proteins as well as the lipoprotein complex "surfactant" and promote tissue repair following injury, mainly through differentiation into ATI cells (Jansing et al., 2017). It is currently assumed that critical events in the pathogenesis of IPF include repetitive injuries of ATII cells such as chronic endoplasmic reticulum stress (Korfei et al., 2018) and subsequent accumulation of cellular dysfunctions such as loss of stemness, increased apoptosis, and induction of senescence, among others (Tanjore et al., 2011; Hill et al., 2019; Parimon et al., 2020). Additionally, dysfunctional ATII cells promote the accumulation of fibrotic lesions by paracrine signals that act as pro-fibrotic factors by stimulating proliferation and differentiation of resident MSCs and lipofibroblasts into myofibroblasts (Tanjore et al., 2011; Selman and Pardo, 2012, 2014). ATII cells may directly contribute to lung fibrosis by undergoing epithelial-to-mesenchymal transition (EMT) and inducing the expression of components of the ECM, although this possibility is still debated (Kim et al., 2006; Tanjore et al., 2009; Rock et al., 2011; Todd et al., 2012). In line with the critical role in lung fibrosis, hyperplastic ATII pneumocytes have been found in lung biopsies of patients suffering from pulmonary fibrosis (PF) (Kulkarni et al., 2016). The molecular mechanisms responsible for the aberrant activation and dysfunction of AECs still remain poorly understood, although reactivation of molecular signaling pathways involved in lung development such as Wnt- $\beta$-catenin, Sonic Hedgehog, and Notch may play a decisive role in this process (Selman et al., 2008; Aoyagi-Ikeda et al., 2011; Baarsma and Konigshoff, 2017).

The Wnt- $\beta$-catenin signaling pathway is involved in numerous cellular processes. In the absence of canonical Wnt ligands, a multiprotein destruction complex facilitates phosphorylation of serine residues in the $\mathrm{N}$-terminus of cytosolic $\beta$-catenin leading to $\beta$-catenin ubiquitination and proteasomal degradation (Clevers, 2006). Binding of Wnt to Frizzled receptors prevents $\beta$-catenin phosphorylation and degradation, resulting in the accumulation of $\beta$-catenin proteins in the nucleus and the activation of down-stream genes after binding to the transcription factor $\mathrm{T}$-cell factor (TCF)/lymphoid enhancer factor (LEF) (Baarsma and Konigshoff, 2017). In addition to canonical Wnt-dependent $\beta$-catenin activation, other Wnt-independent pathways stimulate $\beta$-catenin signaling (Aktary et al., 2016). The tetrameric serine/threonine protein kinase casein kinase 2 (CK2) was identified as a critical factor for $\beta$-catenin signaling. CK2 inhibits different components of the multiprotein disruption complex responsible for $\beta$-catenin degradation and indirectly promotes $\beta$-catenin phosphorylation at Ser 522 , thus increasing $\beta$-catenin protein stability (Gao and Wang, 2006; Ponce et al., 2011). In addition, CK2 strengthens $\mathrm{LEF} / \beta$-catenin interactions by direct phosphorylation of LEF resulting in stronger transactivation of target genes (Wang and Jones, 2006).

The aberrant activation of $\beta$-catenin promotes differentiation of MSCs into myofibroblasts and thus plays a critical role in lung fibrosis. Wnt- $\beta$-catenin signaling is activated in ATII cells following bleomycin-induced lung injury, a well-established experimental model of lung fibrosis (Chen et al., 2016; Baarsma and Konigshoff, 2017). The inhibition of the Wnt- $\beta$-catenin signaling pathway ameliorates bleomycin-induced PF in mice, mainly by attenuating the secretion of pro-fibrotic cytokines such as the transforming growth factor $\beta-1$ (TGF $\beta-1$ ) by ATII cells (Chen et al., 2016). Increased Wnt- $\beta$-catenin signaling has been observed in clinical samples derived from PF patients, which further supports the critical role of this pathway in lung fibrosis (Chilosi et al., 2003; Konigshoff et al., 2008, 2009; Baarsma and Konigshoff, 2017).

NUMB protein was originally discovered in Drosophila melanogaster, as a cell fate determinant in the development of bristles, peripheral sensory organs of the fly (Uemura et al., 1989). In mammals, NUMB homologs are encoded by two different genes: Numb and Numblike (Numbl; Gulino et al., 2010). Mouse NUMB seems to exert broader functions when compared with the Drosophila homolog, probably due to the presence of four different isoforms generated by alternative splicing (Dho et al., 1999; Verdi et al., 1999). NUMB contains two main domains: a N-terminal phospho-tyrosine-binding domain (PTB) and a C-terminal proline-rich domain (PRR) that are both affected by alternative splicing: the NUMB 1 and 2 splicing isoforms carry a short amino acid sequence insert within the PTB domain, which is not present in the NUMB 3 and 4 splicing isoforms. The insert mediates the association of NUMB to the plasma membrane. Hence, NUMB 1 and 2 are membrane-associated while NUMB 3 and 4 accumulate in the cytoplasm. Moreover, NUMB 1 and 3 contain a large amino acid sequence insert within the PRR domain that is not present in the other isoforms (Dho et al., 1999).

NUMB controls numerous biological processes such as endocytosis, cell adhesion, cell polarity, and migration, among others. Previous studies revealed that NUMB proteins play a critical role in the regulation of different signaling pathways including Notch, Sonic Hedgehog, and p53 (Gulino et al., 2010). Numb is essential for mouse development, and Numbdeficient mice die around embryonic day 11.5 (E11.5) due to severe neural defects. In contrast, Numbl knockout mice do not show any obvious developmental phenotype (Zhong et al., 2000; Petersen et al., 2002). NUMB is highly expressed in mammalian lung, but its role in PF remains largely uncharacterized. Interestingly, recent work demonstrated that NUMB promotes epithelial-to-mesenchymal transition (EMT) in response to TGF$\beta 1$ stimulation in ATII cells in vitro, although the underlying molecular mechanisms have not been characterized further (Zhang et al., 2018).

Here, we demonstrate that NUMB plays a critical role in the stimulation of $\beta$-catenin signaling in lung epithelial cells both in vivo and in vitro. We found that inactivation of Numb and Numblike in the lung epithelium diminishes the formation of ATII cells, reduces $\beta$-catenin signaling, and 
attenuates lung fibrosis following bleomycin-induced lung injury. Our experiments show that NUMB forms a molecular complex with CK2 and promotes $\beta$-catenin activation in a CK2dependent manner.

\section{MATERIALS AND METHODS}

\section{Generation of Lung Epithelial Conditional NUMB Knockout Animals (Numb/l dKO)}

Numb-floxed mice were provided by Zilian et al. (2001) and crossed with constitutive Numblike knockout (KO) animals (Petersen et al., 2004). For the generation of lung epithelial Numb cKO animals, we used a tetracycline inducible system (Tet-On system). Numblike KO/Numb-floxed mice were bred with transgenic animals expressing the reverse tetracycline transactivator (rtTA) under the control of the human SPC promoter and the Cre recombinase under the control of the tet operator (SPCrtTA//tetOCre; Perl et al., 2002). This system allows the expression of the Cre recombinase in the lung epithelium upon administration of doxycycline in drinking water, resulting in recombination of the Numb-floxed alleles. To trace Cre expression and for fluorescence-activated cell sorting (FACS), mice were crossed with Rosa26-Stopflox-EYPF reporter line (obtained from Jackson Laboratory).

\section{Animal Husbandry, Bleomycin Administration, and Measurement of Lung Mechanics}

All animal experiments were performed in accordance with the Guide for the Care and Use of Laboratory Animals published by the National Institutes of Health and were approved by the local authorities (RP Darmstadt).

Animals were housed in individual ventilated cages with food and water provided ad libitum on a 12-h-based light/dark cycle. For bleomycin treatment, 10-12-week-old male mice were injected intratracheally with $2.5 \mathrm{U} / \mathrm{kg}$ bleomycin (Bleomedac ${ }^{\circledR}$ ) dissolved in $0.9 \% \mathrm{NaCl}$ solution. Mice were sacrificed 14 or 21 days post-injury as indicated. Control mice were treated with $0.9 \% \mathrm{NaCl}$ as vehicle. The measurement of lung mechanics was performed using the flexiVent ${ }^{\mathrm{TM}}$ system $\left(\mathrm{SCIREQ}^{\circledR}, \mathrm{Emka}\right.$ Technologies) as described previously (Al-Tamari et al., 2018).

\section{Tissue Preparation, Immunohistochemistry, and Immunofluorescence}

Mice were narcotized and subjected to trans-cardiac perfusion with phosphate-buffered saline (PBS). Lungs were cannulated via the trachea, inflated with $1 \%$ PFA and fixed in situ for 5 min at room temperature (RT). The lungs were then ligated, dissected from the thoracic cavity, and fixed for additional $2 \mathrm{~h}$ in $4 \%$ PFA at $4^{\circ} \mathrm{C}$. After incubation, the lungs were washed extensively in PBS and incubated with $30 \%$ sucrose at $4^{\circ} \mathrm{C}$ overnight. After incubation, tissues were embedded in Tissue-Tek ${ }^{\circledR}$ for cryosections or in paraffin. For paraffin sections, fixed lungs were dehydrated through a series of graded ethanol baths. Samples were incubated in isopropanol for $2 \mathrm{~h}$ at $\mathrm{RT}$ and transferred to a solution of isopropanol/paraffin $(1: 1)$ at $65^{\circ} \mathrm{C}$ for $2 \mathrm{~h}$ before embedding in $100 \%$ paraffin at $65^{\circ} \mathrm{C}$.

Hematoxylin and eosin ( $\mathrm{H} \& \mathrm{E})$ staining was performed on paraffin sections following standard procedures. Briefly, sections were deparaffinized by washing twice in xylene and rehydrated by incubation in decreasing concentrations of ethanol to ultrapure water. Sections were transferred in Mayer's hematoxylin (Waldeck) for $10 \mathrm{~min}$ at RT, washed twice in tap water, dipped 10 times in $2 \% \mathrm{HCl} / 70 \%$ ethanol, and washed twice in double distilled water. Slides were then stained with eosin (Waldeck) for 7 min. Samples were dehydrated through a series of ethanol baths to xylene and mounted with Entellan (Merck). The degree of fibrosis was assessed according to the Ashcroft score as described previously (Ashcroft et al., 1988; Al-Tamari et al., 2018). The score scales the grade of fibrotic changes in histological lung samples numerically (from 0 to 8 : 0 : normal lung; 1: minimal fibrous thickening of bronchial and epithelial walls; 2-3: moderate thickening without damage of lung architecture; 4-5: fibrosis with damage of lung architecture and accumulation of fibrous masses; $6-7$ : severe distortion of lung structure and large fibrous areas; and 8: total fibrous obliteration of the field). At least 30 sections from each individual lung were scanned and analyzed in a single-blinded manner. Images were acquired with a Keyence BZ-9000 microscope.

For immunofluorescence staining, fixed cells or tissue cryosections were blocked and permeabilized with $1 \%$ bovine serum albumin (BSA)/5\% goat serum/0.3\% Triton X-100 for 15 min. After treatment, samples were incubated overnight with appropriate primary antibody diluted in $1 \% \mathrm{BSA} / 5 \%$ goat serum/0.1\% Triton X-100 in a humidified chamber at $4^{\circ} \mathrm{C}$. On the next day, samples were washed five times in PBS and incubated with fluorophore-conjugated secondary antibodies for $1 \mathrm{~h}$ at RT. Slides were washed three times in PBS, and cellular nuclei were counterstained using 4',6-diamidino-2phenylindole (DAPI). The slides were mounted with Mowiol ${ }^{\circledR}$ (Millipore). Images were captured using a confocal scanner microscope (CLSM-Leica-TCS SP2). The following primary antibodies were used in this study: anti- $\beta$-catenin (Cell Signaling Technology; \#9562), anti-pro-SPC (Millipore; ab3786), anti-Ecadherin (Abcam; ab11512), and anti-NUMB (Cell Signaling Technology; \#2756) antibodies.

\section{Measurement of Collagen Content in Whole-Lung Homogenates}

Collagen content in whole-lung homogenates was measured using the Sircol ${ }^{\mathrm{TM}}$ Collagen Assay Kit (Biocolor Ltd.) following the manufacturer's instructions.

\section{Isolation of Primary Lung Epithelial Cells and FACS}

Primary lung epithelial cells were isolated as described previously (Driscoll et al., 2012). Cells were resuspended in FACS sorting buffer (0.5 M EDTA, pH 8.0, 1 M HEPES in PBS) and subjected to FACS using a BD FACSAria ${ }^{\mathrm{TM}}$ III flow cytometer (BD Biosciences) equipped with a 405/488/561/633 four-laser system. 


\section{Cell Culture and Treatment}

MLE12 lung epithelial cells were purchased from ATCC and cultivated in DMEM (Sigma-Aldrich) supplemented with $10 \%$ fetal calf serum (FCS, Sigma-Aldrich), $100 \mathrm{U} / \mathrm{ml}$ penicillin, $0.1 \mathrm{mg} / \mathrm{ml}$ streptomycin, and $2 \mathrm{mM}$ glutamine (Sigma-Aldrich) at $37^{\circ} \mathrm{C}$ in a humidified atmosphere with $5 \% \mathrm{CO}_{2}$. For bleomycin treatment, cells were incubated with $50 \mu \mathrm{g} / \mathrm{ml}$ bleomycin $\left(\right.$ Bleomedac $^{\circledR}$ ) for $24 \mathrm{~h}$ before harvest.

\section{Generation of Stable Cell Lines}

Stable scramble and Numb knockdown cells were generated using lentiviral-driven expression of shRNA as previously described (Ianni et al., 2017). In this study, the following shRNAs were used: scramble shRNA: CCTAAG GTTAAGTCGCCCTCGCTCGAGCGAGGGCGACTTAACCTT AGG-3'; Numb shRNA: CCGGGCTGGTTAGAAGAAG TGTCAACTCGAGTTGACACTTCTTCTAACCAGCTTTTTG. For generation of stable MLE12 cells expressing enhanced green fluorescent protein (eGFP)-tagged human NUMB 1-4, $\mathrm{N}$-terminal eGFP-fused $N U M B$ isoforms were cloned into the lentiviral vector pCL6-EG-wo. Lentiviral particles were generated by co-transfection of 293T HEK cells with pCL6-EG-wo vector, the helper plasmid $\mathrm{pCD} / \mathrm{NL}-\mathrm{BH}$, and the envelope plasmid pcoPE in a ratio of 5:5:1. After transfection, lentiviral particles were harvested and used for MLE12 cell transduction as already described (Gorgens et al., 2014). eGFP-positive cells were isolated using flow cytometric cell sorting.

\section{RNA Extraction and Quantitative RT-PCR}

Total RNA from cultivated cells or homogenized lung tissues was extracted using peqGOLD ${ }^{\circledast}$ TriFast $^{\mathrm{TM}}$ reagent (Peqlab) following the manufacturer's instructions. cDNA was synthetized using SuperScript ${ }^{\mathrm{TM}}$ II Reverse Transcriptase kit (Invitrogen). The synthetized cDNA was diluted 1:20 in distilled water and used as template for qPCR. Quantification of the relative mRNA expression was achieved by employing the TaqMan ${ }^{\circledR}$ Gene Expression Assay using a StepOnePlus Real-Time PCR System (Applied Biosystems). Gapdh was used as a loading control. The quantification of the relative expression of the analyzed genes was calculated using the $\Delta \Delta \mathrm{Ct}$ method (Livak and Schmittgen, 2001) using the StepOne ${ }^{\mathrm{TM}}$ Software v2.3. The following TaqMan ${ }^{\circledR}$ probes were used in this study: Numb (Mm01302750_m1), Numbl (Mm01171278_m1), Spc (Mm00488146_g1), Cc10 (Mm01230908_m1), Podoplanin (Mm01348912_g1), Foxj1 (Mm01267279_m1), Ascl2 (Mm01268891_g1), Colla1 (Mm00801666_g1), Ctgf (Mm01192933_g1), Acta2 (Mm00725412_s1), Wisp1 (Mm01200484_m1), Fibronectin (Mm01256744_m1), Snai1 (Mm00441533_g1), Twist1 (Mm00442036_m1), Axin1 (Mm01299060_m1), Tgf- $\beta 1$ (Mm01178820_m1), and Gapdh (Mm99999915_g1).

\section{Western Blot Analysis and Co-immunoprecipitation}

Protein lysates from cultivated cells or homogenized tissues were obtained by resuspending the samples in protein lysis buffer (66 mM Tris- $\mathrm{HCl}$ and 2\% SDS) supplemented with protease and phosphatase inhibitors $(0.5 \mu \mathrm{g} / \mathrm{ml}$ benzamidine, $2 \mu \mathrm{g} / \mathrm{ml}$ aprotinin, $2 \mu \mathrm{g} / \mathrm{ml}$ leupeptin, $2 \mathrm{mM}$ PMFS, $1 \mathrm{mM} \mathrm{Na} 3 \mathrm{VO}_{4}$, and $20 \mathrm{mM} \mathrm{NaF}$ ). Protein lysates were sonicated and clarified by centrifugation. Protein concentrations were determined with the DC ${ }^{\mathrm{TM}}$ Protein Assay Kit (Bio-Rad). Equal amounts of proteins were prepared in protein lysis buffer containing a final concentration of 15\% glycerol, $50 \mathrm{mM}$ dithiothreitol (DTT), and bromophenol blue. The samples were boiled at $95^{\circ} \mathrm{C}$ for $5 \mathrm{~min}$ and resolved by western blotting using standard procedures. The following primary antibodies were used in this study: antiNUMB (Cell Signaling Technology; \#2756), active non-phospho$\beta$-catenin (Cell Signaling Technology; \#8814), pan $\beta$-catenin (Cell Signaling Technology; \#9562), Anti-Tag (CGY)FP (Evrogen; ab121), cortactin (Cell Signaling Technology; \#3502), CK2 $\alpha$ (Cell Signaling Technology; \#2656), CK2 $\beta$ (Thermo Fisher Scientific; \#PA5-27416), AKT (Cell Signaling Technology; \#2967), p-AKT (Abcam: ab133458), and GAPDH (Cell Signaling Technology; 2118). The intensity of bands was quantified using Image Lab ${ }^{\mathrm{TM}}$ software (version 6.0.1; Bio-Rad Laboratories) and normalized to loading controls. The normalized signal of the control sample for each experiment was set to 100 . The abundance of target protein is displayed as fold change relative to controls (relative expression). Co-immunoprecipitation experiments were performed as already described (Ianni et al., 2017, 2021). The following antibodies were used in this study: anti-NUMB (Cell Signaling Technology; \#2756), anti-Tag (CGY)FP (Evrogen; ab121), CK2 $\alpha$ (Thermo Fisher Scientific; \#LF-MA0223), and cortactin (Upstate; 05-180).

\section{Mass Spectrometry Analysis for Identification of NUMB Interactor Partners}

NUMB interactor partners in MLE12 lung epithelial cells were identified using mass spectrometry analysis. Stable eGFP and NUMB-1-eGFP-overexpressing cells were subjected to co-immunoprecipitation using GFP-Trap ${ }^{\circledR}$ _MA Beads (ChromoTek) following manufacturer's instructions. The immunoprecipitates were resolved by SDS-PAGE and subjected to in gel digestion and mass spectrometry (MS) analysis. SDSPAGE gels were stained with InstantBlue ${ }^{\mathrm{TM}}$ Staining Kit (Instant Blue, Expedeon) as recommended by the manufacturer. Gel lanes were cut into $1-\mathrm{cm}^{2}$ squares and collected in Eppendorf tubes. Gel pieces were destained in $50 \mathrm{mM}$ ammonium bicarbonate $(\mathrm{ABC}) / 50 \%$ ethanol for $20 \mathrm{~min}$ at room temperature and dehydrated with $100 \%$ ethanol. Proteins were reduced by incubation with $10 \mathrm{mM}$ dithiothreitol (DTT) at $56^{\circ} \mathrm{C}$ for $45 \mathrm{~min}$ and then alkylated with $55 \mathrm{mM}$ iodoacetamide (IAA)/50 mM $\mathrm{ABC}$ for $30 \mathrm{~min}$. Samples were washed sequentially with the following: $50 \mathrm{mM} \mathrm{ABC}, 100 \%$ ethanol, $50 \mathrm{mM} \mathrm{ABC}$, and then twice in $100 \%$ ethanol. Peptide digestion was performed with $4.6 \mathrm{ng} / \mathrm{\mu l}$ trypsin in $50 \mathrm{mM} \mathrm{ABC}$ overnight at $37^{\circ} \mathrm{C}$. On the next day, the supernatant containing digested peptides was collected into separate tubes. Gel pieces were incubated with increasing concentrations of acetonitrile [30\% acetonitrile/ $3 \%$ trifluoroacetic acid (TFA) for $20 \mathrm{~min}, 70 \%$ acetonitrile for $20 \mathrm{~min}$, and then twice with $100 \%$ acetonitrile for $20 \mathrm{~min}$ ]. In 
each step, the supernatant containing extracted peptides was collected and mixed together. Digested peptides were mixed $1: 1$ with a solution of $5 \%$ acetonitrile and $1 \%$ trifluoroacetic acid. Peptides were separated using a binary buffer system of buffer $\mathrm{A}\left[0.1 \%(v / v)\right.$ formic acid in $\left.\mathrm{H}_{2} 0\right]$ and $\mathrm{B}[0.1 \%$ $(v / v)$ formic acid in $80 \%$ acetonitrile] on an EASY nanoflow HPLC system (Thermo Fisher Scientific, Odense Denmark) and loaded on $50-\mathrm{cm}$ columns (75 $\mu \mathrm{m}$ ID) packed in-house with $\mathrm{C} 18$ resin $(1.9 \mu \mathrm{m}$ diameter). The HPLC was coupled to a quadrupole-based mass spectrometer Q Exactive (Thermo Fisher Scientific, Bremen, Germany) via a nanoelectrospray ionization source (Thermo Fisher Scientific, Bremen, Germany). MS spectra were acquired at a resolution of 70,000 $(200 \mathrm{~m} / \mathrm{z})$ in a mass range of $350-1,650 \mathrm{~m} / \mathrm{z}$. Tandem mass spectrometry (MS/MS) events were measured in a data-dependent mode for the 10 most abundant peaks (Top10 method) in the high mass accuracy Orbitrap after HCD (higher-energy C-trap dissociation) fragmentation at 25 collision energy in a $100-1650 \mathrm{~m} / \mathrm{z}$ mass range. The resolution was set to 17,500 at $200 \mathrm{~m} / \mathrm{z}$ combined with an injection time of $60 \mathrm{~ms}$.

Raw files were processed using MaxQuant (1.3.0.5) and the implemented Andromeda search engine. For protein assignment, electrospray ionization (ESI)-MS/MS fragmentation spectra were correlated with the UniProt mouse database (downloaded 2011), including the human NUMB protein (P49757) and a list of common contaminants. Searches were performed with tryptic digestion specificity allowing two missed cleavages and a mass tolerance of 4.5 parts per million (ppm) for MS and $6 \mathrm{ppm}$ for MS/MS spectra. Carbamidomethyl at cysteine residues was set as a fixed modification, whereas oxidation at methionine and acetylation at the $\mathrm{N}$-terminus were defined as variable modifications. The minimal peptide length was set to seven amino acids and the false discovery rate for proteins and peptides below $1 \%$, using the implemented decoy algorithm. For label-free quantification, the minimum ratio was set to 2. Significantly enriched proteins were identified using a twosided Student's $t$-test between control (eGFP) and eGFP-NUMB1 immunoprecipitations. Targets enriched more than twofold in the eGFP-NUMB1 immunoprecipitations as compared to controls $(p$-value $<0.05)$ were considered as potential NUMB 1 interactor partners.

\section{Statistical Analysis}

Data are expressed as the mean \pm standard deviation (SD) of at least three independent biological replicates. Statistical significance was assessed by Student's $t$-test or one-way ANOVA as indicated in each experiment using GraphPad Prism 5.0 software.

\section{RESULTS}

\section{Inactivation of Numb in MLE12 ATII Cells Attenuates Activation of $\beta$-Catenin Signaling Following Bleomycin Exposure}

We were intrigued by a recent study, reporting that NUMB promotes bleomycin-induced PF through a yet unknown molecular mechanism (Zhang et al., 2018). To gain further insight into the biological function of NUMB in lung epithelial cells, we generated stable MLE12 ATII cell lines lacking NUMB expression by using a shRNA targeting Numb. Western blot analysis confirmed efficient inhibition of NUMB expression in this cell line (Figure 1A). Since the activation of Wnt$\beta$-catenin signaling in lung epithelial cells plays a critical role in promoting lung fibrosis, we analyzed whether NUMB influences the expression and activation of $\beta$-catenin. Importantly, we observed a substantial reduction of total and active $\beta$-catenin levels in Numb knockdown (KD) cells as compared to scramble controls (Figure 1B). An immunofluorescence analysis for $\beta$-catenin confirmed these data and revealed a dramatic reduction in the amount of membrane-associated $\beta$-catenin in NUMBdepleted cells (Figure 1C). To analyze whether NUMB influences $\beta$-catenin activation following bleomycin-induced injury, we analyzed the expression of total and active $\beta$-catenin in control and Numb KD MLE12 cells after exposure to bleomycin for $24 \mathrm{~h}$. Repression of Numb massively suppressed the activation of $\beta$-catenin in response to bleomycin, suggesting that NUMB enables $\beta$-catenin signaling following injury (Figure 1D). Interestingly, bleomycin treatment did not only strongly induce expression of $\beta$-catenin but also of NUMB, further arguing for a potential supportive role of NUMB in $\beta$-catenin activation (Figure 1D). To validate these results, we determined the expression of known $\beta$-catenin target genes in NUMB-depleted cells following bleomycin treatment by quantitative RT-PCR (RTqPCR). We found that Numb KD cells showed substantially lower expression of several $\beta$-catenin target genes as compared with control cells, which corresponded to reduced $\beta$-catenin levels (Figure 1E). Bleomycin treatment also increased Numb mRNA expression, suggesting that increased levels of NUMB protein are due to enhanced transcription or RNA stabilization (Figure 1E). Taken together, our data provide compelling evidence that NUMB promotes the activation of $\beta$-catenin signaling in injured lung epithelial cells.

\section{Numb and Numblike Are Required for the Generation of Normal Numbers of ATII Cells and $\beta$-Catenin Localization in Mice}

Next, we investigated whether NUMB exerts similar functions in lung epithelial cells in mice. Since global inactivation of Numb in mice results in embryonic lethality (Zhong et al., 2000), we generated lung epithelial conditional Numb knockout animals (Numb cKO) using a tetracycline-inducible system (Figure 2A). We generated mice (Numb cKO) carrying a floxed Numb allele $\left(N u m b^{f l / f l}\right)$, which expresses the tetracycline transactivator (rtTA) under control of the lung epithelial specific promoter Spc (SPCrtTA) (Perl et al., 2002) and the Cre recombinase under the control of the tet operator (SPCrtTA//tetOCre). The doxycycline (Dox)-dependent expression of Cre recombinase allows specific deletion of Numb in lung epithelial cells (Figure 2A). To avoid possible compensatory effects by the Numb homolog Numblike, we additionally introduced a Numblike knockout allele into Numb cKO animals, which was feasible since Numblike germ line mutants do not show any obvious developmental 


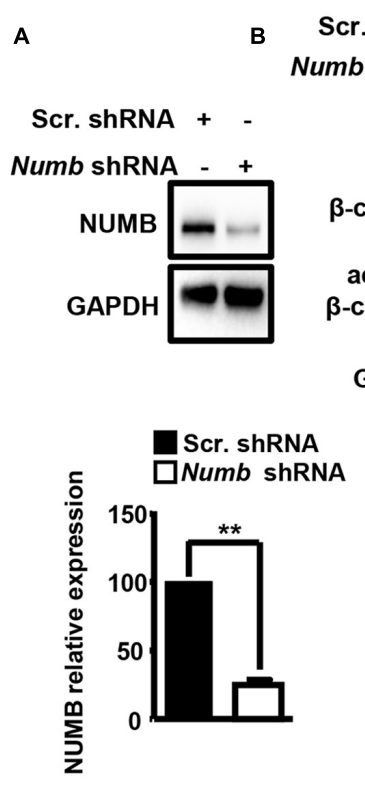

D

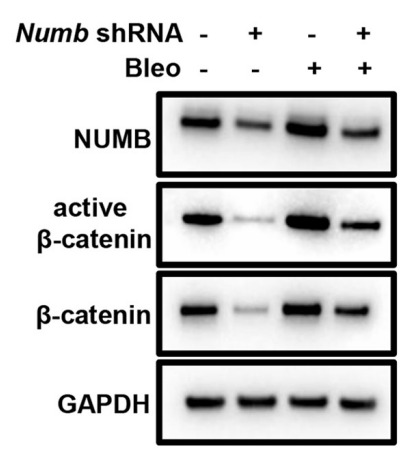

E

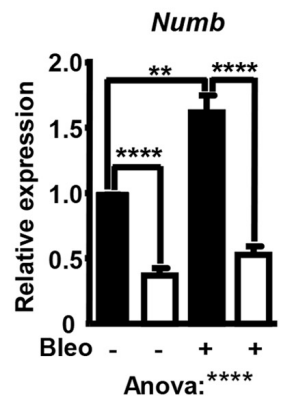

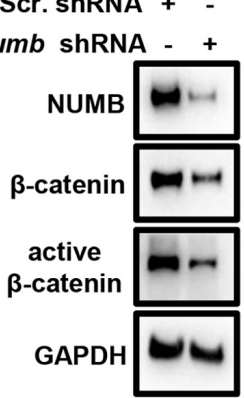

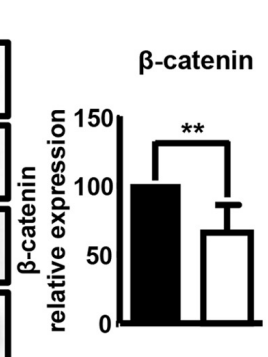

Scr. ShRNA $\square$ Numb ShRNA

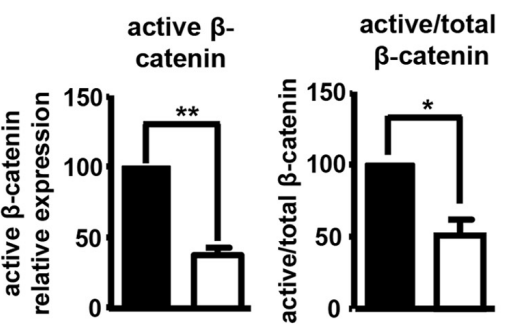

C

Scr. ShRNA
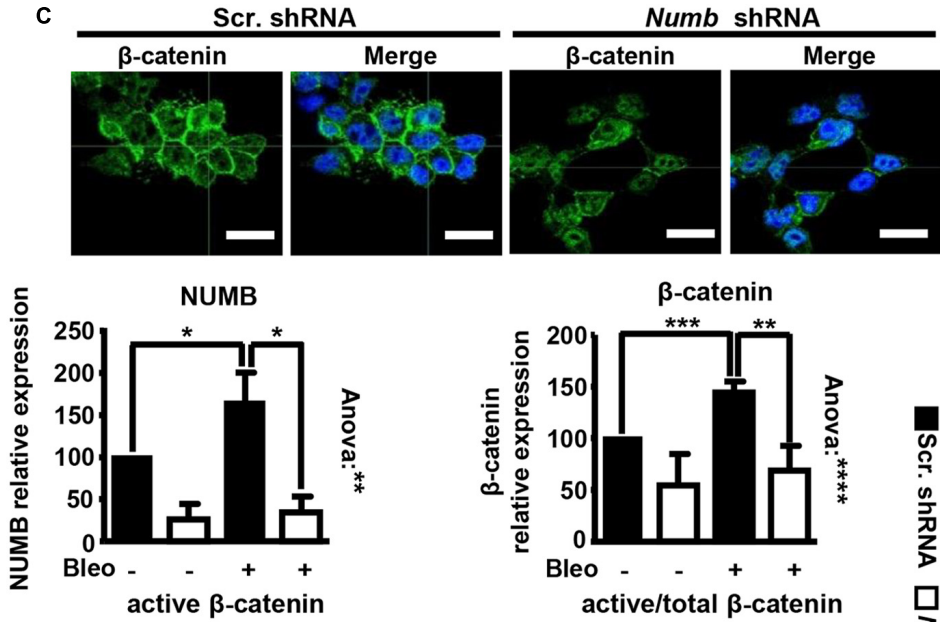

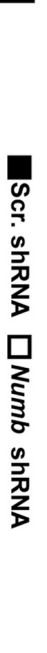
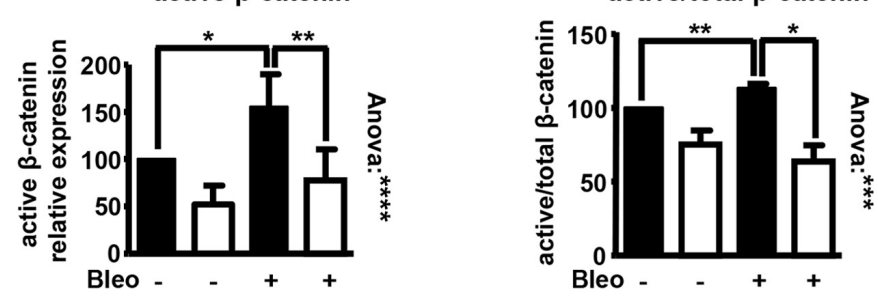

Scr. ShRNA $\square$ Numb shRNA
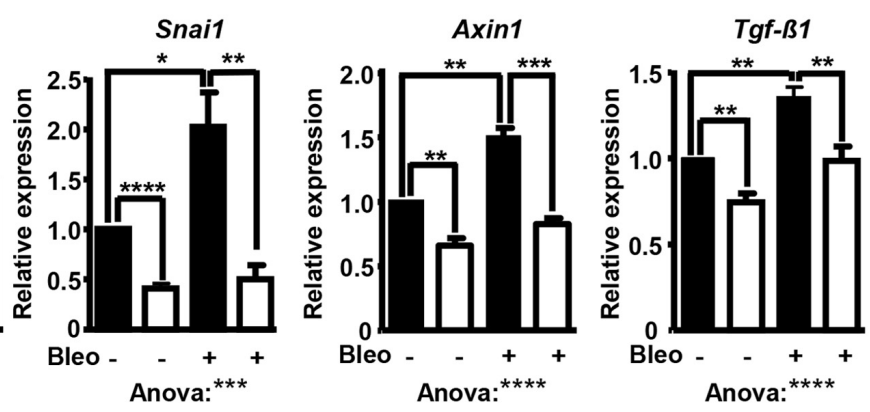

FIGURE 1 | Depletion of NUMB in lung epithelial cells attenuates $\beta$-catenin signaling in vitro. (A) Western blot analysis of NUMB in MLE12 lung epithelial cells stably expressing scramble or Numb-targeting shRNA. GAPDH was used as a loading control. Quantification of NUMB expression \pm SD is shown in the graph below $\left(n=3 ;{ }^{* *} p<0.01\right.$; Student's $t$-test). (B) Western blot analysis of total and active $\beta$-catenin in scramble and Numb knockdown (KD) cells. GAPDH was used as a loading control. Quantification of total and active $\beta$-catenin relative to GAPDH and active/total $\beta$-catenin \pm SD is shown on the right $(n=6$ for total $\beta$-catenin and $n=3$ for active $\beta$-catenin; ${ }^{*} p<0.05,{ }^{* *} p<0.01$; Student's $t$-test). (C) Immunofluorescence (IF) staining of Numb KD cells for total $\beta$-catenin (green). Nuclei were counterstained with DAPI $(n=3$; scale bar $=15 \mu \mathrm{m})$. (D) Western blot analysis for total and active $\beta$-catenin in scramble and Numb KD cells, $24 \mathrm{~h}$ after treatment with bleomycin. GAPDH was used as loading control. Quantification of NUMB and of total and active $\beta$-catenin expression \pm SD is shown on the right. Statistical significance between two specific groups was assessed by Student's $t$-test. Analysis of variance between all measured groups was done using the one-way ANOVA test $\left(n=4 ;{ }^{*} p<0.05,{ }^{\star \star} p<0.01,{ }^{\star \star *} p<0.001,{ }^{\star \star \star \star} p<0.0001\right)$. (E) RT-qPCR analysis of known $\beta$-catenin target genes (Wisp 1, Snai1, Axin1, and Tgf- $\left.\beta 1\right)$ in scramble and Numb KD cells $24 \mathrm{~h}$ after bleomycin treatment. Efficient inhibition of Numb in KD cells was assessed by RT-qPCR. $\beta$-Actin was used as a loading control. Quantification of average mRNA levels relative to $\beta$-actin $\pm S D$ is shown in the histograms $\left(n=6 ;{ }^{*} p<0.05,{ }^{* *} p<0.01 ;{ }^{* * *} p<0.001\right.$, and ${ }^{* * * *} p<0.0001$; Student's $t$-test and one-way ANOVA as indicated). 
A
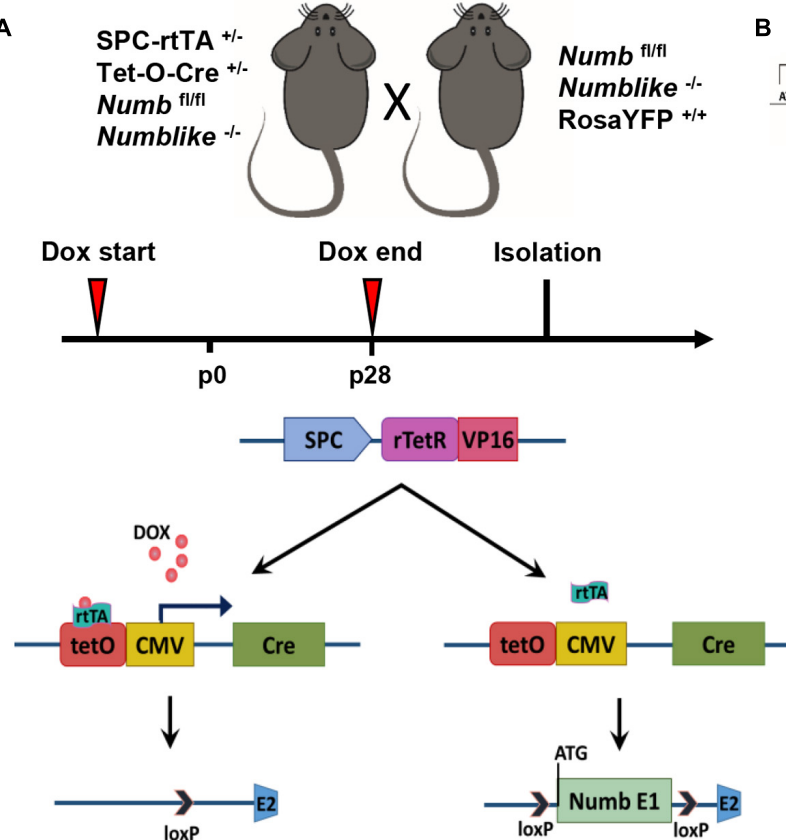

Knockout allele
Numb fl/fl

Numblike -t-

RosaYFP +/+

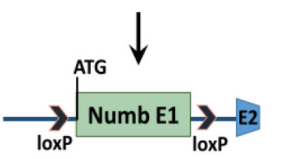

Conditional allele
B

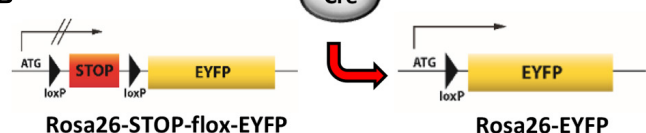

C

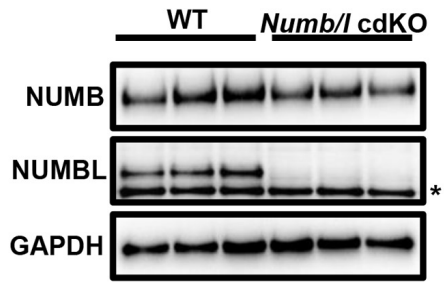

E

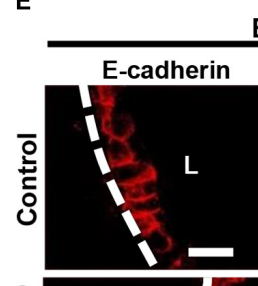

Bronchial epithelium

$F$
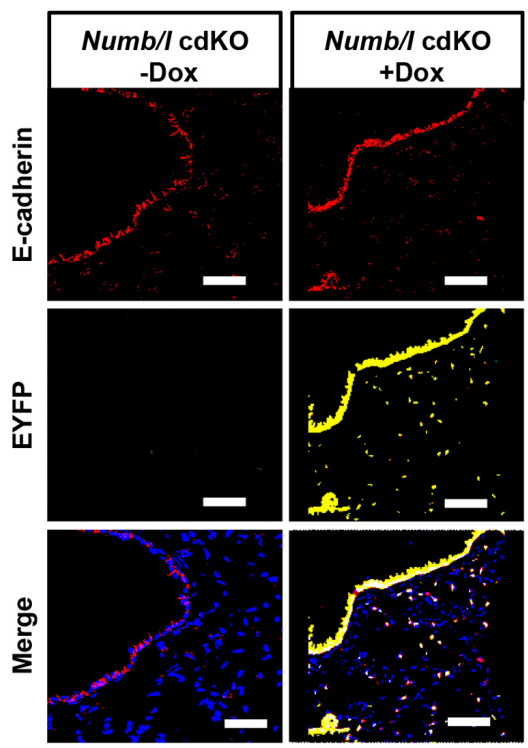

D $\square \mathrm{WT} \square$ Numb/l cdKO

$\square \mathrm{WT} \square$ Numb/l cdKO
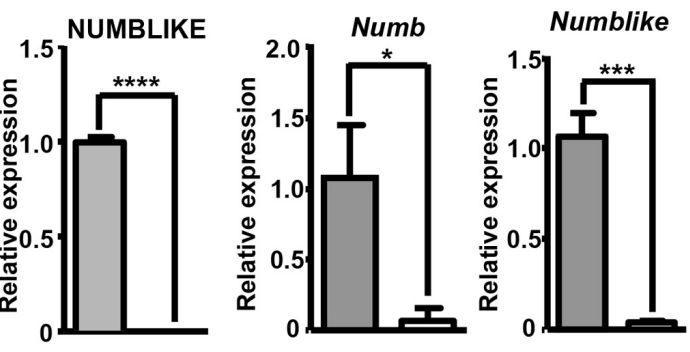

Alveolar epithelium

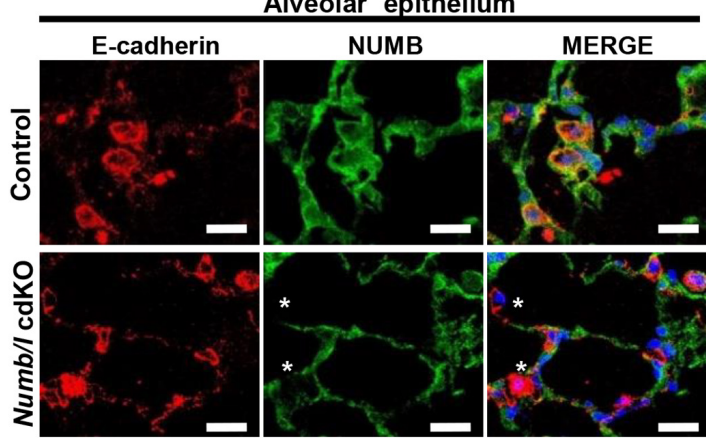

FIGURE 2 | Generation and characterization of Numb/l cdKO animals. (A) Schematic model illustrating the strategy for generation of Numb/l cdKO animals. (B) A schematic representation of the Rosa26-STOP-flox-EYFP transgenic mice used to identify Cre recombinase activity in lung epithelial cells (upper panel). Immunofluorescence staining of lung cryosections from Numb/l cdKO animals carrying ROSA26-EGFP reporter gene without and with Dox treatment. The proximal and distal EYFP-labeled cells (yellow) and E-cadherin-positive (E-cadherin; red) lung epithelial cells are clearly visible. (C) Western blot analysis of NUMB and NUMBLIKE expression in whole-lung homogenates derived from WT and Numb/l cdKO animals. GAPDH was used as a loading control. The asterisk indicates a non-specific band. Quantification of NUMB and NUMBLIKE relative to GAPDH \pm SD is shown on the right $\left(n=3\right.$; ${ }^{*} p<0.05$, ${ }^{* \star \star *} p<0.0001$; Student's $t$-test). (D) RT-qPCR analysis of Numb (left panel) and Numblike (right panel) expression in FACS-sorted lung epithelial cells derived from WT and Numb/l cdKO mice. The graph represents the average relative expression $\pm \mathrm{SD}$ of the indicated gene of three independent animals $\left(n=3 ;{ }^{*} p<0.05,{ }^{* \star *} p<0.001\right.$; Student's $t$-test). (E,F) Immunofluorescence staining for NUMB (green) and E-cadherin (red) of lung sections derived from control and Numb/l cdKO adult mice (8 weeks old). Efficient depletion of NUMB in the bronchial $(\mathbf{E})$ and alveolar epithelium $\mathbf{( F )}$ is clearly discernible. Asterisks indicate NUMB-depleted E-cadherin-positive cells. Scale bars $=12 \mu \mathrm{m}$. 
phenotype (Petersen et al., 2002). We also added a Rosa26-EYFP allele to the SPCrtTA//tetOCre//Numb fl/fl//Numblike - $^{-}$ strain, which expresses EYFP after Dox-mediated activation of Cre recombinase expression and subsequent recombination, to enable tracing of recombined cells in vivo (Figure 2B). Hereafter, we refer to SPCrtTA//tetOCre// Numb $b^{f / f l} / / N u m b l i k e^{-/-} / /$Rosa26-EYFP mice as Numb/l cdKO and Numb $b^{f l / f l} / / N u m b l i k e^{-/-} / /$Rosa26-EYFP as control mice. To ensure complete recombination of the Numb $b^{f / f l}$ alleles, Numb/l cdKO mice received Dox via the drinking water throughout gestation until postnatal stage p28 (Wert et al., 1993; Perl et al., 2002). Immunofluorescence staining of lung sections from Numb/l cdKO mice for EYFP verified that the activity of the Cre recombinase was restricted to the alveolar and bronchiolar lung epithelium (Figure 2B). No EYFP signal was detected in control Numb/l cdKO mice, which did not receive Dox treatment, confirming the validity of our model.

In order to demonstrate efficient inactivation of Numb and Numblike (Numbl) in knockout mice, we performed a $\mathrm{RT}^{-T a q M a n}{ }^{\circledR}$ gene expression analysis. As expected, cdKO mice showed a complete absence of Numbl expression. Numb mRNA levels were reduced in total lung homogenates, although the difference did not reach significance (Supplementary Figure 1A). In contrast, western blot analysis demonstrated a significant reduction of NUMB and NUMBL proteins in cdKO animals compared to controls (Figure 2C). We assume that the expression of Numb outside epithelial cells obscures depletion in the epithelium. Therefore, we took advantage of the EYFP reporter to specifically isolate lung epithelial cells by fluorescence-activated cell sorting (FACS; Supplementary Figure 1B). As expected, we measured a virtually complete absence of Numb and Numbl expression in FACS-isolated $\mathrm{EYFP}^{+}$-cells from cdKO animals (Figure 2D). To further confirm efficient depletion of NUMB in the lung epithelium, we performed co-staining of NUMB and the epithelial marker E-cadherin by immunofluorescence on lung sections derived from control and Numb/l cdKO Rosa26-EYFP ${ }^{-/-}$embryos (Supplementary Figure 1C). As expected, we observed a colocalization of NUMB with E-cadherin in the lung epithelium of control animals, which was absent in Numb/l cdKO mice (Supplementary Figure 1C). Similar results were obtained in adult animals, where NUMB was detected in E-cadherin-positive bronchial and alveolar epithelial cells of wild-type but not Numb/l cdKO animals (Figures 2E,F, respectively). Numb/l cdKO mice were born at Mendelian ratio and did not show any gross morphological abnormalities. However, a more refined analysis revealed a substantial reduction of mRNA expression of the well-established ATII cell marker Spc in Numb/l cdKO mice compared to control animals, whereas the expression of the Club cell marker Cc10, the ATI cell marker Podoplanin, the ciliated cell marker Foxj1, and the neuroendocrine cell marker Ascl2 was not changed (Figure 3A). In line with this finding, an immunofluorescence analysis of pro-SPC-positive cells followed by a morphometric analysis revealed a reduction of ATII cells of approximately $30 \%$ in $\mathrm{Numb} / \mathrm{l} \mathrm{cdKO}$ mice as compared to control littermates (Figure 3B). We concluded that NUMB is required for the generation of regular numbers of ATII cells in the lung epithelium but not for their proper positioning or normal lung morphogenesis. The normal expression of Club, ATI, neuroendocrine, and ciliated cell markers but not of ATII markers strongly suggested that only ATII but no other epithelial cells were reduced in Numb/l cdKO mice, although such an extrapolation has to be viewed with some caution.

To investigate whether the absence of NUMB has an impact on the distribution and expression of $\beta$-catenin in lung epithelial cells in vivo, we stained lung sections from adult Numb/l cdKO mice for $\beta$-catenin. Strikingly, we observed a profound reduction of $\beta$-catenin in the ATII cell-containing alveolar epithelium and a shift of $\beta$-catenin from a mostly lateral to a basolateral position in Numb mutant bronchial epithelial cells (Figure 3C). In contrast, western blot analysis did not reveal a significant reduction of $\beta$-catenin levels in whole-lung lysates from Numb/l cdKO mice (Figure 3D), since the presence of other cell types expressing high levels of $\beta$-catenin in the lung obscured the reduction of $\beta$-catenin levels in ATII cells. Taken together, our results clearly indicate that the absence of Numb/l in lung epithelial cells leads to a severe disorganization of $\beta$-catenin in bronchial cells and a dramatic reduction of $\beta$-catenin expression in alveolar epithelial cells.

\section{NUMB-Dependent Activation of $\beta$-Catenin Signaling Requires CK2}

To investigate the molecular mechanism governing NUMBmediated stimulation of $\beta$-catenin signaling, we searched for potential novel NUMB interaction partners (Figure 4A). Stable MLE12 cells expressing eGFP-tagged NUMB were subjected to immunoprecipitation using GFP-Trap ${ }^{\circledR}$ _MA beads, and co-precipitated proteins were analyzed by mass spectrometry (Figure 4A). In line with already described functions of NUMB (Gulino et al., 2010), we found that NUMB interacts with several proteins involved in cellular vesicle assembly, cell-cell contact formation, and other cellular functions (Figure 4B, Supplementary Figure 2A, and Supplementary Table 1). In addition, we identified several novel interaction partners, including cortactin (cttn) and the CK2 $\alpha$ (Csnk2al) and $\beta$ subunits (Csnk2b) (Figure 4B and Supplementary Table 1). To validate the mass spectrometry results, we performed co-immunoprecipitation experiments in MLE12 cells stably expressing different NUMB isoforms (NUMB 1-4) fused to eGFP (Figure 4C). Cortactin and CK2 $\alpha$ and $\beta$ robustly co-precipitated with both NUMB 1 and NUMB 2 while negligible interactions were detected with the other NUMB isoforms (Figure 4C). These results suggest that the amino acid insert in the PTB domain, which is only present in the NUMB 1 and 2 isoforms, is critical for the interaction with cortactin and CK2 $\alpha$ and $\beta$ (Figure 4C). In addition, we found that NUMB 1 co-localizes with cortactin, while depletion of NUMB in MLE12 cells caused aberrant subcellular localization of cortactin (Supplementary Figures 2B,C). Since CK2 plays a critical role in $\beta$-catenin activation (Gao and Wang, 2006; Ponce et al., 2011), we further characterized the interaction between NUMB and CK2. Co-immunoprecipitation experiments using scramble and Numb shRNA-treated MLE12 cells revealed that not only the transfected NUMB-eGFP fusion proteins but also endogenous NUMB formed a molecular 
A Control $\square$ Numb/l cdKO

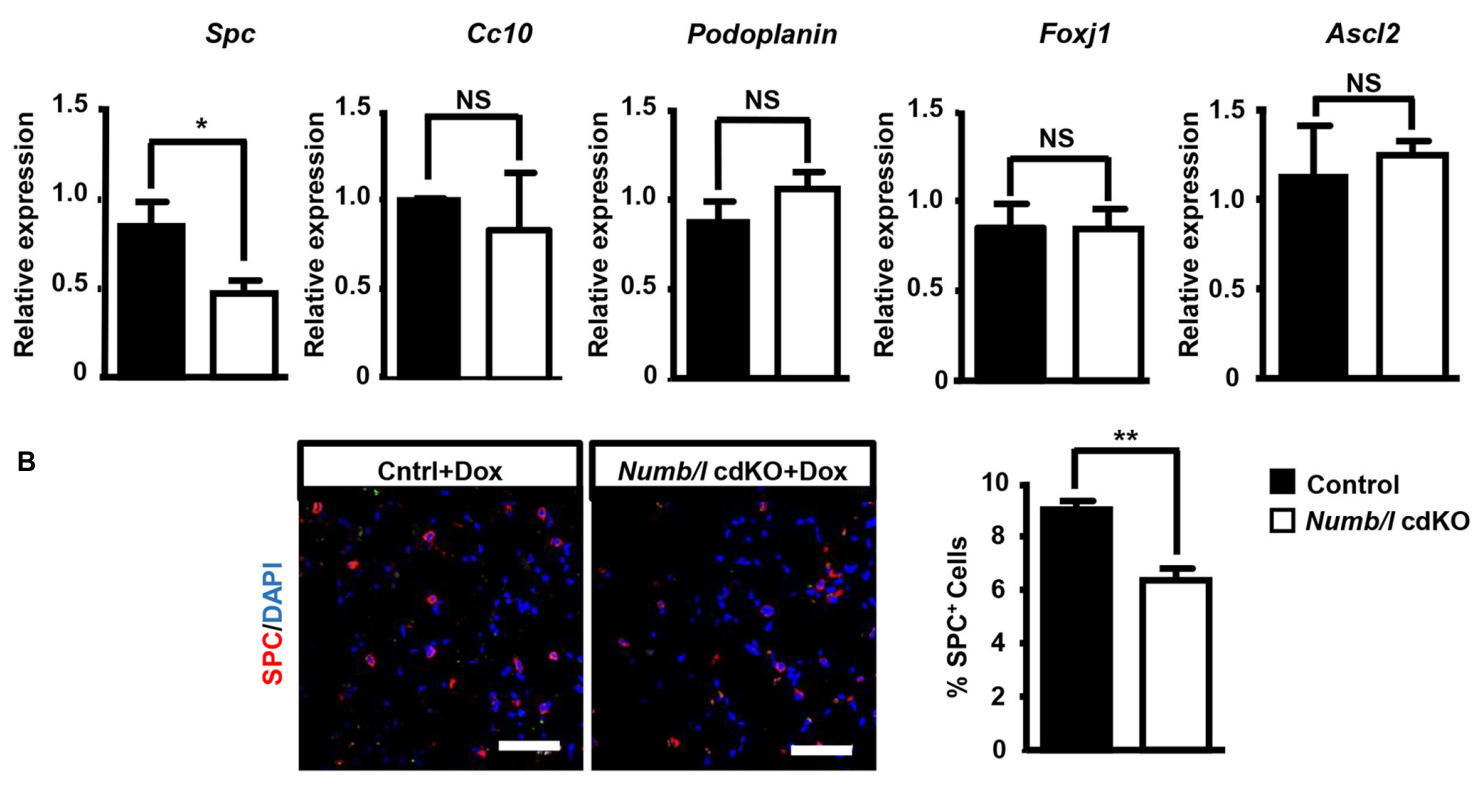

C
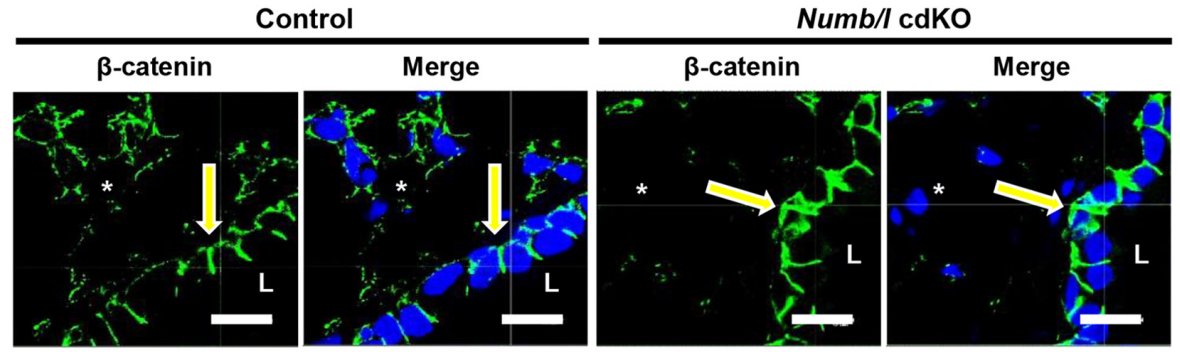

D
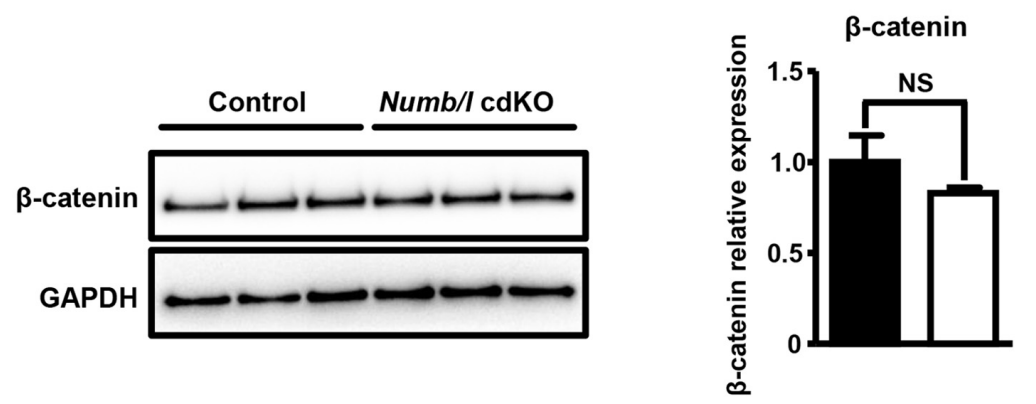

Control

$\square$ Numb/l cdKO

FIGURE 3 | Numb/l are required for generation of normal numbers of ATIl cells in the mouse lung and normal localization of $\beta$-catenin in lung epithelial cells.

(A) RT-qPCR analysis of lung epithelial cell markers (Spc: ATIl cells; Cc10: Club cells; Podoplanin: ATI cells; Foxj1: ciliated cells, and Ascl2: neuroendocrine cells) in total lung homogenates derived from control and Numb/l cdKO mice ( $n=3,{ }^{*} p<0.05$; NS, not significant). (B) Immunofluorescence staining for SPC of lung sections derived from control and Numb/l cdKO animals. Cell nuclei were counterstained with DAPI. Scale bar $=47 \mu \mathrm{m}$. Quantification of SPC-positive cells is shown in the histogram on the right ( $n=3$ per group; $\left.{ }^{* *} p<0.01\right)$. (C) Immunofluorescence staining for $\beta$-catenin of lung sections derived from control and $N u m b / /$ cdKO animals. Cell nuclei were counterstained with DAPI. Scale bar $=12 \mu \mathrm{m}$. Notice the aberrant localization of $\beta$-catenin in bronchial epithelial cells (arrows) and the decline in $\beta$-catenin expression in alveolar cells (asterisks). (D) Western blot analysis of $\beta$-catenin in whole-lung homogenates derived from control and $\mathrm{Numb} / \mathrm{l}$ cdKO animals. GAPDH was used as a loading control. Quantification of $\beta$-catenin expression \pm SD is shown in the graph on the right ( $n=4$; NS, not significant; Student's $t$-test).

complex with CK2 (Figures 4D,E). Interestingly, quantification of CK2 protein levels demonstrated that depletion of Numb in lung epithelial cells significantly reduced the expression of CK2 $\beta$ while the $\alpha$ subunit remained unchanged, indicating that NUMB not only interacts with CK2 $\beta$ but also controls its expression (Supplementary Figure 2D).
Next, we investigated whether NUMB-dependent stimulation of $\beta$-catenin signaling requires $\mathrm{CK} 2$ activity. Exposure of scramble and Numb shRNA-treated cells to bleomycin in the presence or absence of the CK2 specific inhibitor CX-4945 revealed that $\mathrm{Cx}-4945$ efficiently reduced the levels of active and total $\beta$-catenin in scramble control but not in NUMB-depleted 
A

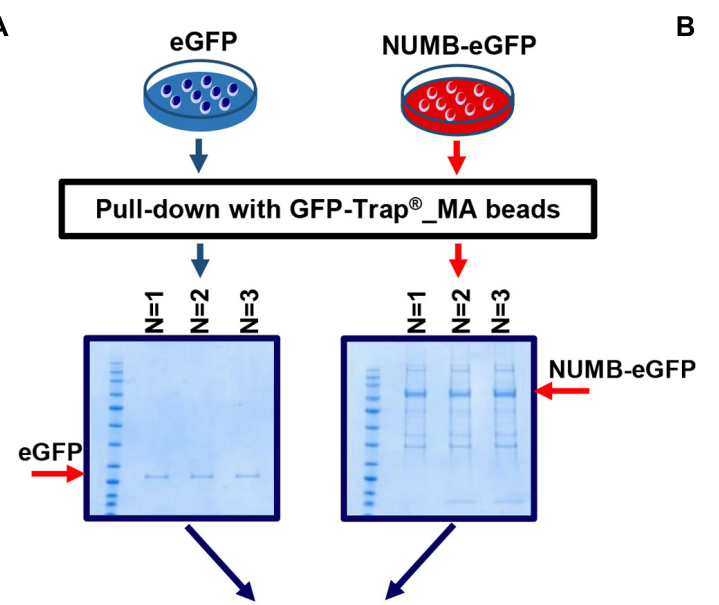

In gel digestion with trypsin

Quantification by MS

C

IP:GFP

NB1 NB2 NB3 NB4 GFP

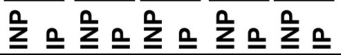
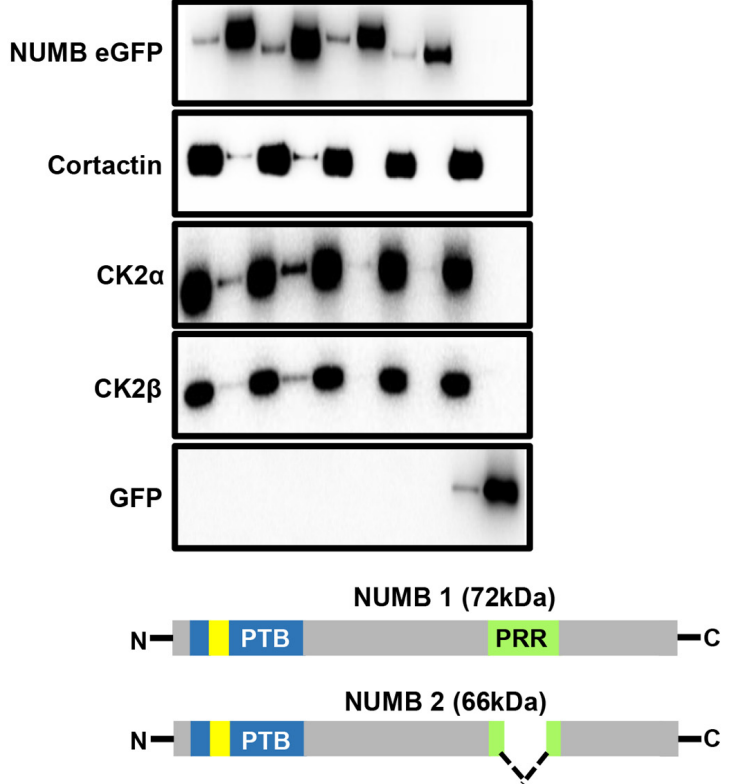

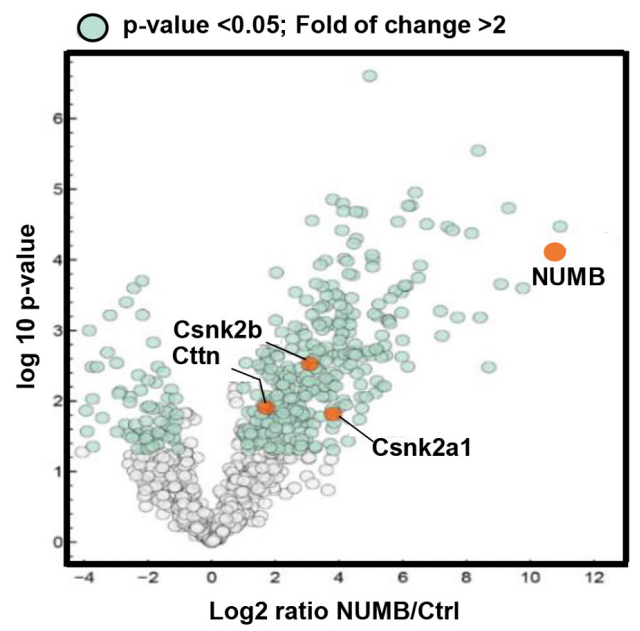

D 을:NUMB

Scr. ShRNA + + -

E $\stackrel{O}{\mathrm{G}} \mathrm{IP:CK2 \alpha}$

Numb ShRNA - - +
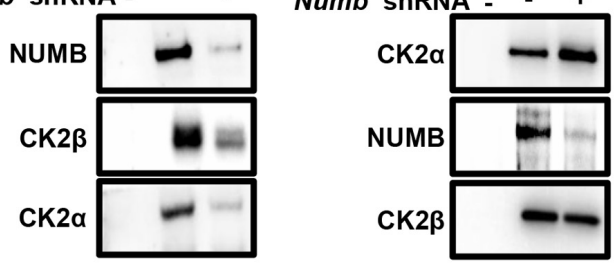

INPUT
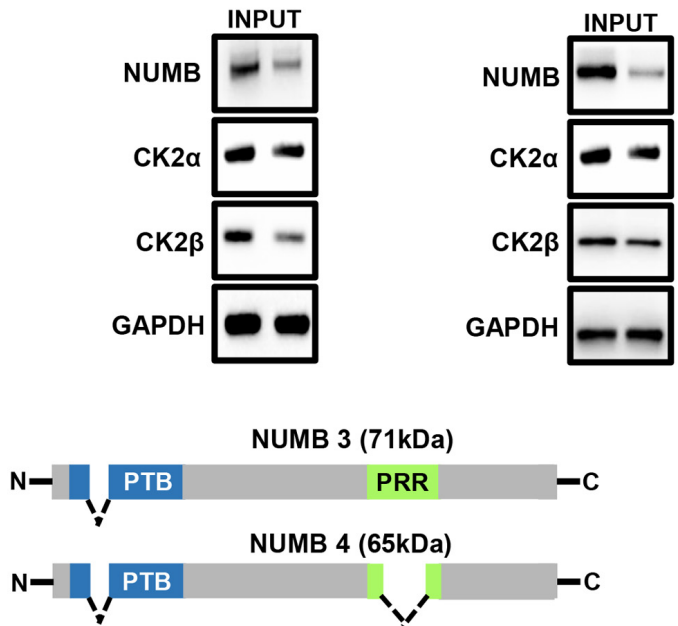

FIGURE 4 | NUMB interacts with different proteins including CK2. (A) A scheme depicting the experimental approach used for mass spectrometry-based analysis of NUMB-eGFP interactor partners. (B) A volcano plot showing NUMB-interacting proteins detected by mass spectrometry. (C) Coupled immunoprecipitation (GFP antibody) and western blot analysis (GFP, cortactin, CK2 $\alpha$, and CK2 $\beta$ antibodies) of stable NUMB 1-4-overexpressing cells $(n=3$; upper panel). The lower scheme illustrates the structure of the four NUMB isoforms (PTB, phospho-tyrosine-binding domain; PRR, proline-rich domain; yellow box, amino acid insert in the PTB domain) that might be responsible for interaction with specific targets. See text for details. (D) Coupled immunoprecipitation (NUMB antibody) and western blot analysis (NUMB, CK2 $\alpha$, and CK2 $\beta$ antibodies) of scramble and Numb KD cells. Non-immune immunoglobulin (IgG) was used as a negative control $(n=3)$.

(E) Coupled immunoprecipitation (CK2 $\alpha$ antibody) and western blot analysis (NUMB and CK2 $\beta$ antibodies) of scramble and Numb KD cells.

cells (Figure 5A). An analysis of AKT phosphorylation at serine 129 (p-AKT), a major target of CK2, confirmed efficient inhibition of CK2 activity by Cx-4945 (Figure 5A; Ponce et al., 2011). Taken together, these data clearly indicate that the presence of NUMB is necessary for CK2-dependent regulation of $\beta$-catenin signaling. Furthermore, we analyzed the expression of total and active $\beta$-catenin in stable NUMB-overexpressing cells in the presence of the CK2 inhibitor $\mathrm{Cx}-4945$. Pharmacological 

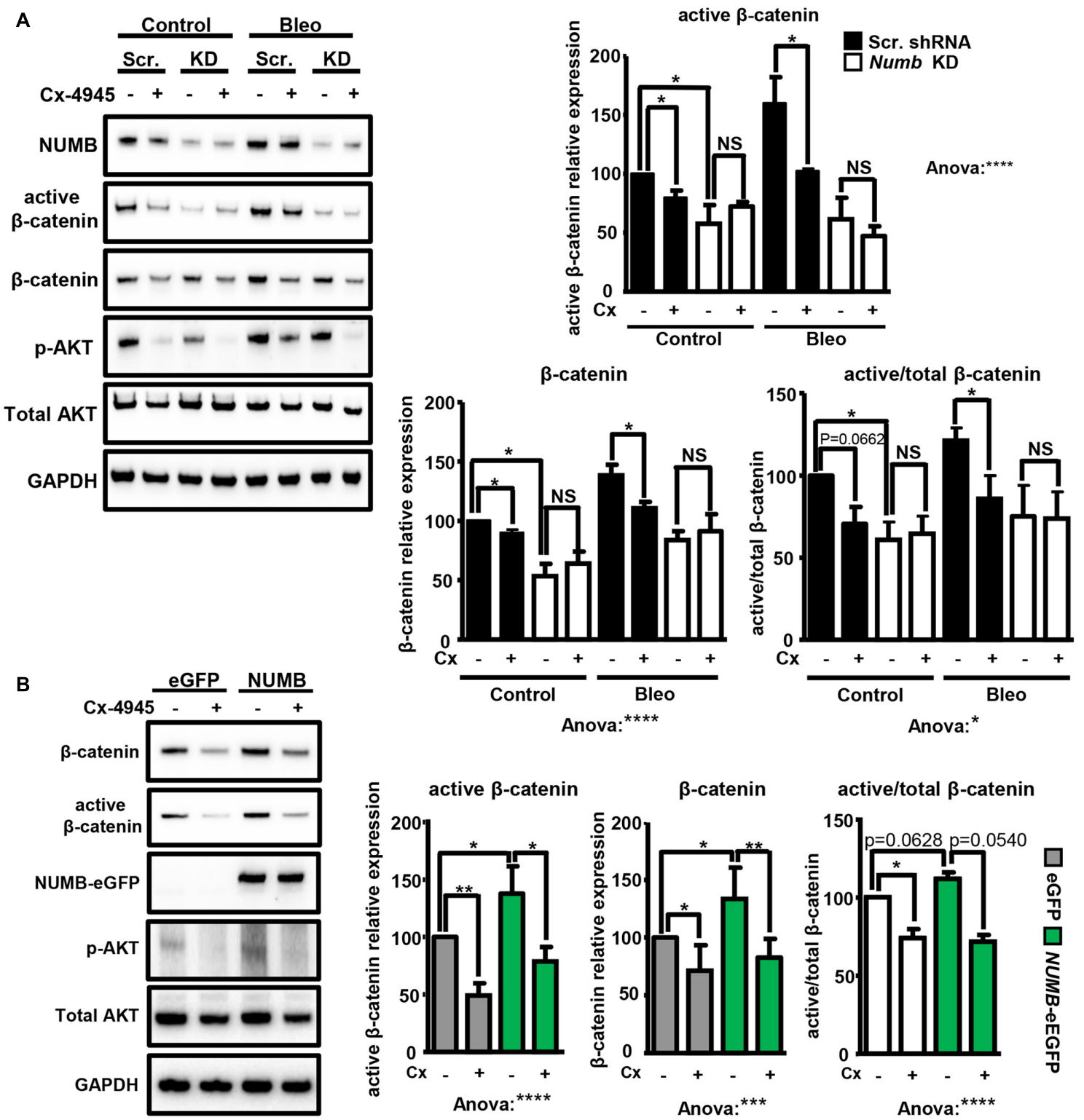

FIGURE 5 | NUMB-dependent activation of $\beta$-catenin requires CK2 activity. (A) Western blot analysis of the levels of indicated markers in scramble (Scr.) and Numb KD MLE12 cells $24 \mathrm{~h}$ after bleomycin treatment in the presence of $10 \mu \mathrm{M}$ CK2 inhibitor Cx-4945 as indicated. Phosphorylated AKT at serine 129 (p-AKT) was used as a positive control to demonstrate efficient inhibition of CK2. GADPH was used as loading control. Quantification of total and active $\beta$-catenin relative levels \pm SD is given in the histograms below $\left(n=4 ;{ }^{*} p<0.05,{ }^{* \star *} p<0.0001\right.$; NS, not significant; Student's $t$-test and one-way ANOVA as indicated). (B) Western blot analysis of active and total $\beta$-catenin expression levels in stable e-GFP-tagged NUMB-overexpressing cells in the presence of Cx-4945 inhibitor for $24 \mathrm{~h}$. GAPDH was used as a loading control. Quantification of active and total $\beta$-catenin relative levels $\pm S D$ is given in the histograms below $\left(n=4\right.$; ${ }^{*} p<0.05$, ${ }^{* *} p<0.01$, Student's $t$-test; One-way ANOVA: $\left.{ }^{* \star \star} p<0.001,{ }^{\star \star \star *} p<0.0001\right)$.

inhibition of CK2 prevented NUMB-mediated stimulation of $\beta$-catenin signaling, corroborating the role of CK2 in NUMBdependent stimulation of $\beta$-catenin (Figure 5B).

\section{Loss of Numb/l Ameliorates Bleomycin-Induced Lung Fibrosis in vivo}

To analyze whether attenuation of $\beta$-catenin signaling in Numb/l cdKO mice protects against PF, we injected control and mutant mice with bleomycin and determined the expression of total and active $\beta$-catenin in whole-lung homogenates 14 days after injury. In line with previous results (Li et al., 2015; Chen et al., 2016; Cao et al., 2018), control mice showed a strong increase of total and active $\beta$-catenin after bleomycin injection (Figure 6A). In sharp contrast, $\mathrm{Numb} / \mathrm{l}$ cdKO mice displayed negligible $\beta$-catenin activation, indicating a critical role for NUMB in the activation of $\beta$-catenin signaling in vivo (Figure 6A). To validate the inhibition of $\beta$-catenin signaling, we determined the 
A

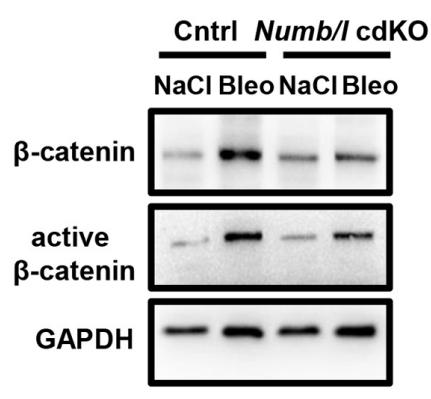

B

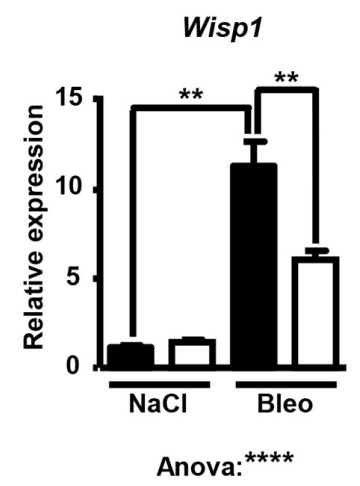

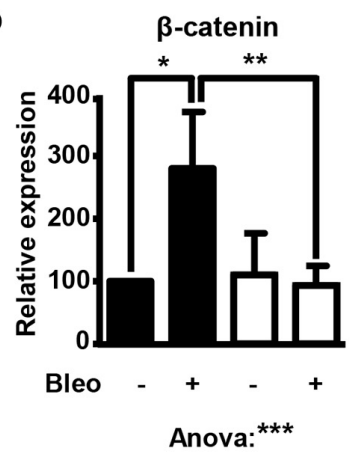

$\beta$-catenin

\section{Control $\square$ Numb/l cdKo}

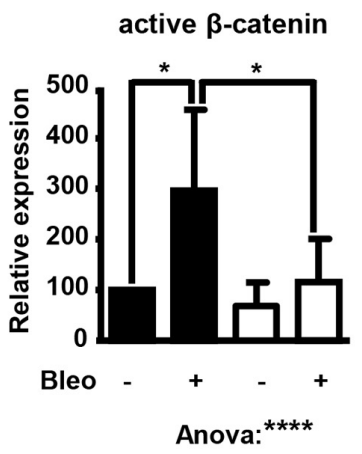

active/total $\beta$-catenin

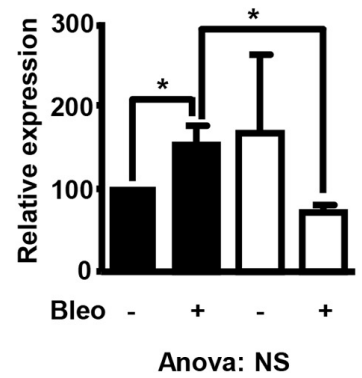

Control $\square$ Numb/l cdKO
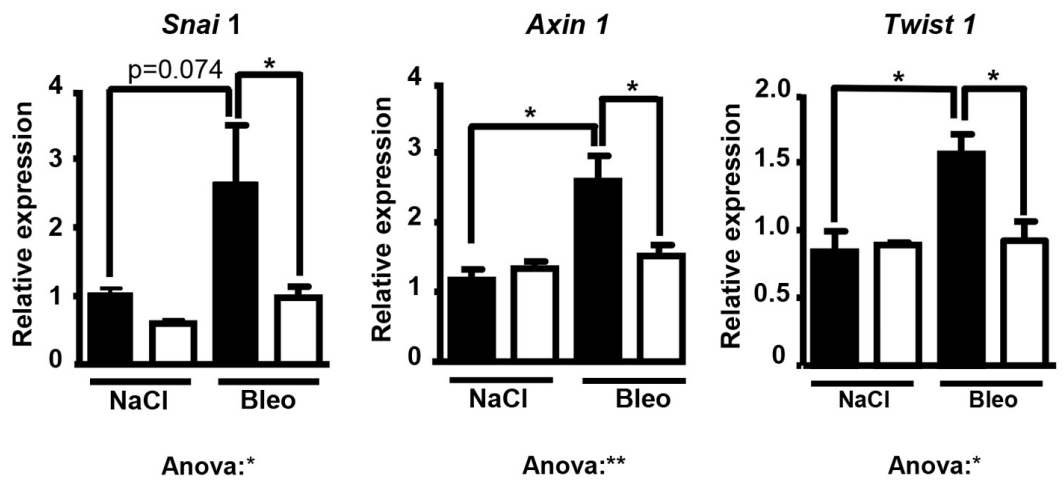

FIGURE 6 | Depletion of NUMB in lung epithelial cells attenuates $\beta$-catenin signaling in vivo following bleomycin injury. (A) Western blot analysis of total and active $\beta$-catenin in lung homogenates from control and Numb/l cdKO animals. GAPDH was used as a loading control. Quantification of total and active $\beta$-catenin expression $\pm S D$ is shown on the right $\left(n=5 ;{ }^{*} p<0.05\right.$, ${ }^{\star \star} p<0.01$, ${ }^{\star \star \star} p<0.001,{ }^{\star \star \star \star} p<0.0001$; Student's $t$-test and one-way ANOVA as indicated). (B) RT-qPCR analysis of $\beta$-catenin target genes in lung homogenates from control and Numb/l cdKO animals 14 days after treatment with vehicle ( $\mathrm{NaCl}$ ) or bleomycin (Bleo) $\left(n=3,{ }^{*} p<0.05,{ }^{* *} p<0.01,{ }^{* \star * *} p<0.0001\right)$.

expression of typical $\beta$-catenin targets, such as Wisp1, Snai1, Axin1, and Twist1 14 days after bleomycin treatment. We found that the absence of $N u m b / l$ strongly attenuated the upregulation of $\beta$-catenin targets compared to control animals (Figure 6B). Since we assumed that accumulation of fibrotic tissue might take longer than the activation of $\beta$-catenin, we examined lung sections 7 days later, at day 21 after bleomycin injury by $H \& E$ staining to examine the consequences of enhanced $\beta$-catenin signaling. Sections were scored for fibrosis according to the Ashcroft method (see "Materials and Methods"), revealing a substantial reduction of fibrosis in $\mathrm{Numb} / \mathrm{l}$ cdKO compared to control animals (Figure 7A). Likewise, electron microscopy and Sircol analysis indicated reduced deposition of collagen fibers in $\mathrm{Numb} / \mathrm{l}$ cdKO mice compared to control animals (Figures 7B,C). To further confirm these findings, we analyzed the expression of genes linked to fibrosis, such as collagen 1 (Col1a1), smooth muscle actin (Acta2), connective tissue growth factor (Ctgf), and fibronectin in whole-lung homogenates from control and $\mathrm{Numb/l}$ cdKO animals 14 days after exposure to bleomycin. In contrast to control littermates, no significant increase was spotted in $\mathrm{Numb} / \mathrm{l}$ cdKO mice providing compelling evidence that depletion of NUMB prevents fibrosis after bleomycin injury (Figure 7D).
An improvement in morphology might not necessarily correspond to improvement in lung function. Therefore, we measured several functional lung parameters in mechanically ventilated control and $N u m b / l$ cdKO animals 14 and 21 days after bleomycin treatment, including volume, static and dynamic compliance, tissue damping, and elastance. Compliance is defined as the change in lung volume that occurs per unit upon change in pressure and therefore provides a direct readout for the elasticity of the lung. Further information is obtained by measurement of static and dynamic compliance, which are determined in the absence of airflow and during rhythmic breathing, respectively. Importantly, depletion of Numb prevented a decline in lung volume and maintained higher static and dynamic compliance following bleomycin injury (Figure 8A). In addition, we measured lung damping and elastance. Lung damping is a parameter that directly correlates with the energy dissipated by the alveoli, whereas elastance, the reciprocal value of compliance, represents the variation in pressure required to change a unit of volume. Both parameters reflect tissue resistance and inversely correlate with lung elasticity. We found that $N u m b / l$ mutant mice showed reduced tissue dampening and strongly improved elasticity compared to 
A

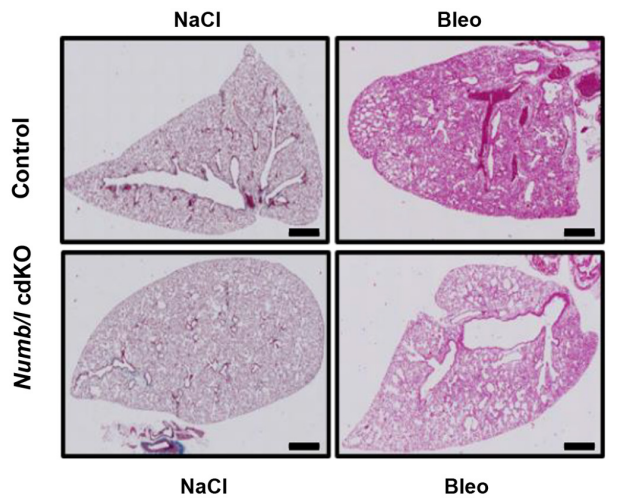

B

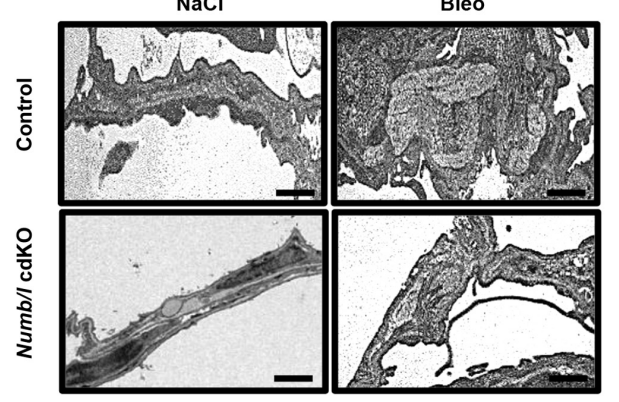

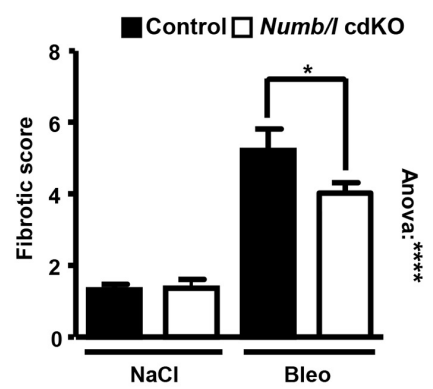

C

$\square$ Control $\square$ Numb/l cdKo

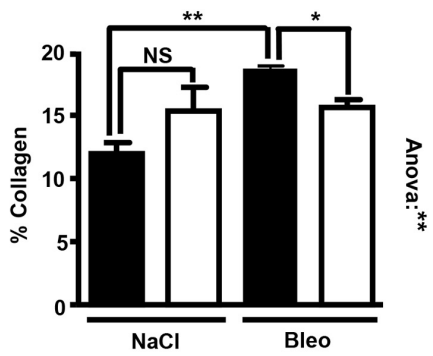

D

$\square$ Control $\square$ Numb/l cdKo
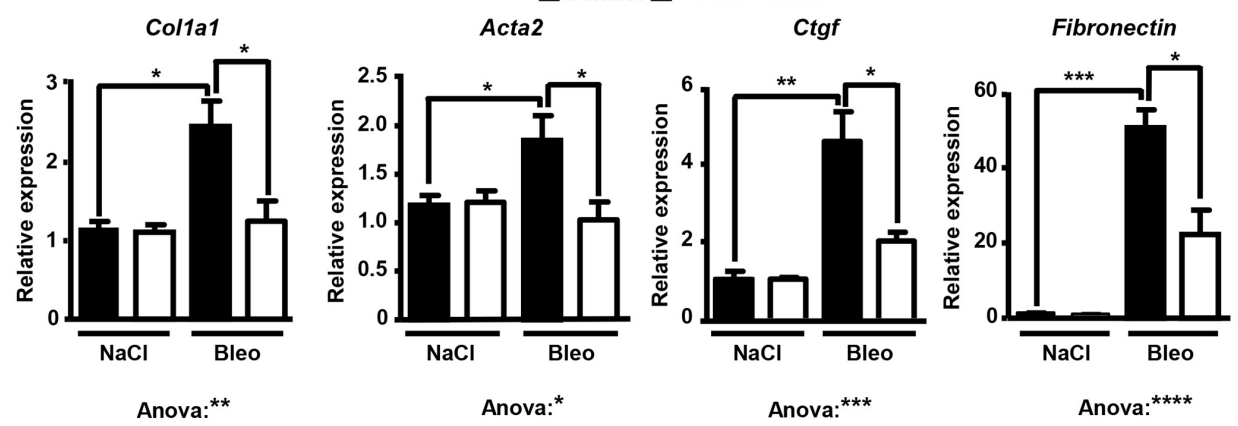

FIGURE 7 | Inactivation of Numb/l in lung epithelial cells ameliorates bleomycin-induced lung fibrosis. (A) H\&E staining of paraffin sections (5 $\mu \mathrm{m}$ ) from Numb/l cdKO vs. control mice 21 days after bleomycin treatment. Scale bar $=1 \mathrm{~mm}$. Quantification of the fibrotic foci is on the right. The fibrotic score was assigned arbitrarily between 0 (non-fibrotic) and 8 (highly fibrotic) using randomly chosen H\&E-stained slides from control and Numb/l cdKO mice (control: $n=3 ; \mathrm{Numb} / \mathrm{cdKO}: n=5$; $\left.{ }^{*} p<0.05,{ }^{* * \star *} p<0.0001\right)$. (B) Electron microscopy analysis of collagen I fiber deposition in control and Numb/l cdKO animals 21 days after treatment with vehicle $(\mathrm{NaCl})$ or bleomycin (Bleo). Scale bar $=1 \mu \mathrm{m}$. (C) Sircol-based analysis of collagen content in whole-lung homogenates derived from control and Numb/l cdKO animals ( $n=4 ;{ }^{*} p<0.05,{ }^{\star *} p<0.01$; NS, not significant). (D) RT-qPCR analysis of pro-fibrotic genes in lung homogenates from control and Numb/l cdKO animals (control: $n=3$; Numb/l cdKO: $n=5 ;{ }^{*} p<0.05,{ }^{* \star} p<0.01,{ }^{* \star *} p<0.001,{ }^{\star \star * *} p<0.0001$ ).

control mice following injury (Figure 8A). Even more striking, inactivation of $\mathrm{Numb} / \mathrm{l}$ dramatically increased survival after bleomycin treatment. Nearly $80 \%$ of $N u m b / l$ cdKO animals were still alive 20 days after the injury, compared to approximately $20 \%$ in the control group (Figure 8B). Taken together, our data indicate that inactivation of $N u m b / l$ in lung epithelial cells greatly ameliorates bleomycin-induced lung fibrosis, most likely by attenuating CK2-dependent $\beta$-catenin activation.

\section{DISCUSSION}

IPF is a progressive disease with a poorly understood etiology. Despite evident signs of increased inflammation, augmented oxidative stress, and aberrant function of the coagulation system, therapeutic approaches based on antioxidants, immunosuppressants, and/or anticoagulants failed to delay the progression of IPF (Demedts et al., 2005; Staitieh et al., 2015; Adegunsoye and Strek, 2016; Magnini et al., 2017). In patients with IPF, the use of the two antifibrotic drugs nintedanib and pirfenidone slows down the decline of lung function and improves outcome, but does not completely stop further deterioration (Korfei et al., 2018). The therapeutic effect of nintedanib and pirfenidone has been recently also proven in other forms of PF, different from IPF, which share the progressive fibrotic phenotype (Maher et al., 2018; Distler et al., 2019; Flaherty et al., 2019). Still, lung transplantation is the only strategy to treat severely ill patients, but prognosis 

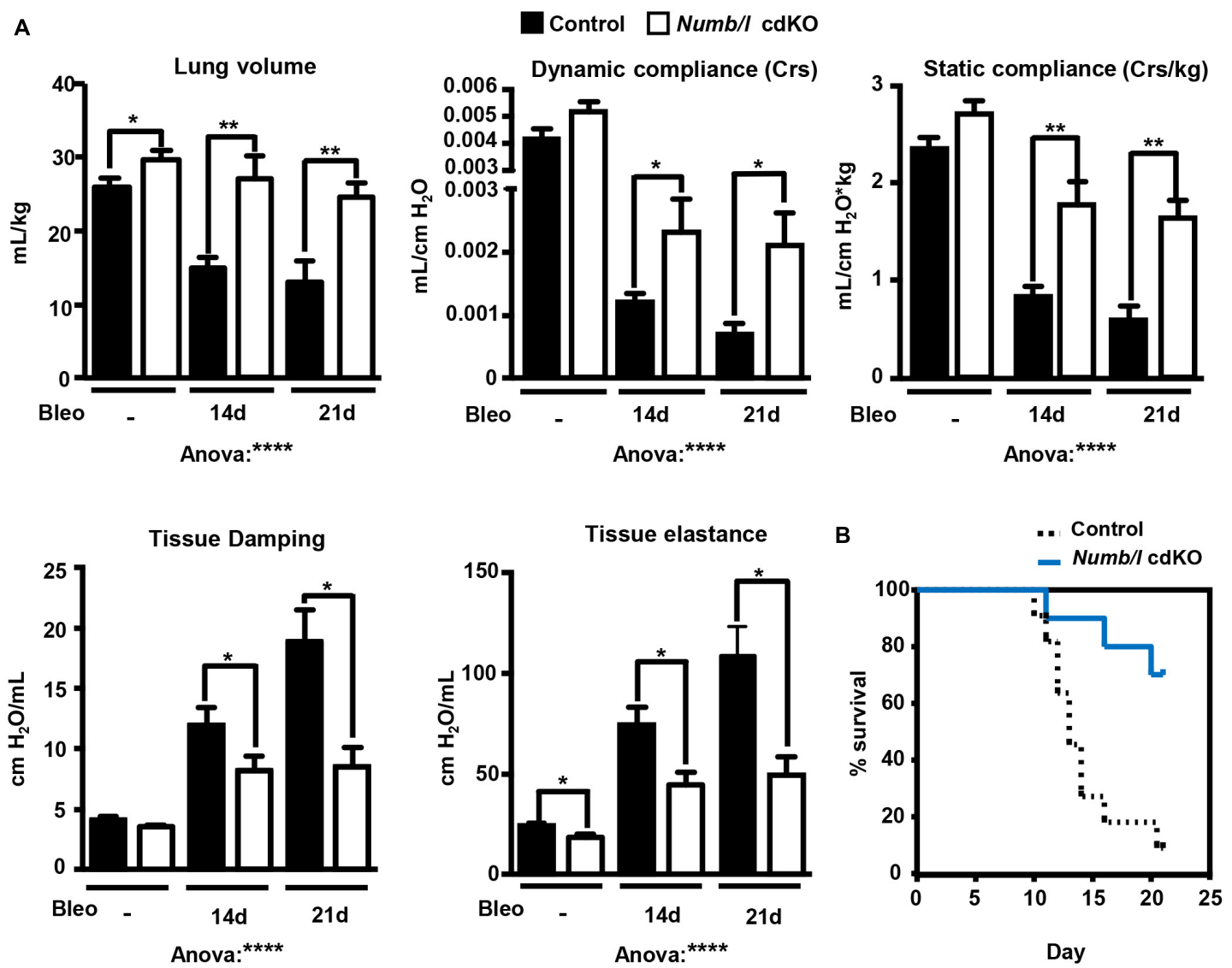

FIGURE 8 | Suppression of Numb/l expression improves lung function and survival after bleomycin treatment. (A) Assessment of physiological lung parameters in control and Numb/l cdKO animals 14 and 21 days after treatment with vehicle (NaCl) or bleomycin (Bleo). Histograms represent the average \pm SD of individual parameters (control with NaCl: $n=8$; Numb/l cdKO with NaCl: $n=7$; control with bleomycin 14 days: $n=10$; Numb/l cdKO with bleomycin 14 days: $n=6$; control with bleomycin 21 days: $n=3$; Numb/l cdKO with bleomycin 21 days: $n=5 ;{ }^{*} p<0.05 ;{ }^{* *} p<0.01$, $\left.{ }^{* * *} p<0.0001\right)$. (B) Survival curves of control ( $n=11$ ) and Numb/l cdKO $(n=10)$ animals after bleomycin treatment.

remains poor after transplantation (Thabut et al., 2009). Thus, a better understanding of the molecular mechanisms driving the pathogenesis of IPF is imperative for the development of novel therapeutic strategies.

Interactions between epithelial cells (especially ATII cells), fibroblasts, and immune cells play a critical role for PF pathogenesis (Parimon et al., 2020). It is widely assumed that repetitive and prolonged damage of lung epithelial cells caused by viral infections, tobacco smoking, and aging causes epithelial cell dysfunction, leading to activation of pro-fibrotic signaling pathways that ultimately promote the accumulation of fibrotic lesions (Parimon et al., 2020). The activation of Wnt- $\beta$-catenin signaling is tightly linked to PF. Numerous studies document hyperactivation of the pathway in experimental models of PF as well as in human patients (Konigshoff et al., 2008; Chen et al., 2016; Baarsma and Konigshoff, 2017). Consistent with these studies, pharmacological inhibition of Wnt$\beta$-catenin attenuates fibrosis in mice (Baarsma and Konigshoff, 2017). It has been reasoned that Wnt- $\beta$-catenin signaling contributes to $\mathrm{PF}$ at different levels. $\beta$-catenin-dependent signals stimulate proliferation and migration of resident fibroblasts (Lam et al., 2011) and promote differentiation of resident mesenchymal stem cells into myofibroblasts ( $\mathrm{Li}$ et al., 2015; Cao et al., 2018). The activation of Wnt- $\beta$-catenin signaling in ATII cells leads to secretion of factors that act on resident mesenchymal stem cells to induce differentiation into myofibroblasts (Wynn, 2011; Aumiller et al., 2013; Chen et al., 2016). In addition, Wnt- $\beta$-catenin stimulates EMT in ATII cells, thus enhancing the expression of components of the ECM responsible for accumulation of fibrotic lesions (Konigshoff et al., 2009; Mutze et al., 2015; Liu et al., 2019).

Despite these insights, the mechanisms responsible for hyperactivation of $\beta$-catenin signaling in lung epithelial cells remain largely unexplored (Konigshoff et al., 2008). Here, we demonstrate that the membrane-associated protein NUMB plays a pivotal role in the regulation of $\beta$-catenin signaling in lung epithelial cells. Inactivation of $\mathrm{Numb} / \mathrm{l}$ in the lung epithelium prevents activation of $\beta$-catenin and attenuates fibrosis, therefore preserving lung functions following bleomycin-induced injury. We reason that NUMBdependent activation of $\beta$-catenin signaling in lung epithelial cells may promote fibrosis by enhanced secretion of cytokines 
such as Wisp1. Consistent with our data, a recent study demonstrated that NUMB is upregulated in fibrotic kidney in vivo where it promotes tissue fibrosis by stimulating EMT of renal epithelial cells (Ding et al., 2015). However, NUMBmediated control of the $\beta$-catenin signaling is apparently complex and cell type-specific. In contrast to its role in fibrotic tissues, NUMB inhibits EMT in breast and ovarian cancer, partially by suppressing $\beta$-catenin signaling ( $\mathrm{Hu}$ et al., 2019; Liang et al., 2019). Such opposing effects in different tissues or cells emphasize a high level of complexity exerted by NUMB in control of the $\beta$-catenin pathway that warrants further investigation.

The exact molecular mechanisms by which NUMB activates $\beta$-catenin signaling in lung epithelial cells require further experiments. Our data demonstrate that NUMB promotes $\beta$-catenin activation in vitro through interaction with CK2, a key molecule involved in $\beta$-catenin stabilization and transcriptional activation (Gao and Wang, 2006; Ponce et al., 2011). We hypothesize that binding of NUMB to CK2 might stimulate its enzymatic activity or modulate CK2 interaction with other proteins, controlling the activation of $\beta$-catenin signaling. Moreover, depletion of Numb decreases CK2 $\beta$ expression in lung epithelial cells, indicating that NUMB might promote $\mathrm{CK} \beta$ stabilization either by direct or indirect mechanisms. Although our study clearly establishes a role of CK2 in NUMB-dependent control of $\beta$-catenin activation, additional studies are clearly required to gain better insights into the underlying molecular mechanisms. Nevertheless, our conclusion is supported by recent studies, which demonstrate critical pro-fibrotic functions of CK2 in the skin and liver (Zhang et al., 2015; Huang et al., 2017), suggesting that NUMB might promote tissue fibrosis by activating the CK2- $\beta$-catenin axis. However, it is possible that NUMB controls different signaling cascades in addition to CK2, which might indirectly activate the $\beta$-catenin pathway. For example, NUMB may either stimulate or inhibit the Notch pathway, depending on the cellular context (McGill and McGlade, 2003; McGill et al., 2009; Luo et al., 2020). Notch signaling, on the other hand, either inhibits or stimulates the Wnt- $\beta$-catenin pathway, raising the possibility that NUMB controls $\beta$-catenin activation at least in part via Notch (Hayward et al., 2005; Kwon et al., 2011; Ishiguro et al., 2017). Finally, NUMB may control the activation of $\beta$-catenin signaling by interfering with its interaction with E-cadherin. This idea is supported by previous studies demonstrating that NUMB and its homolog NUMBL interact with E-cadherin and regulate its subcellular localization (Kuo et al., 2006; Rasin et al., 2007). E-cadherin and $\beta$-catenin are both important components for the maintenance of adherens junction (Harris and Tepass, 2010). It has been proposed that E-cadherin might act as an inhibitor of $\beta$-catenin signaling by sequestering $\beta$-catenin protein, although the fraction of $\beta$-catenin involved in cell-cell contact formation might differ from the fraction involved in Wnt signaling (Hulsken et al., 1994). Decreased E-cadherin- $\beta$-catenin interactions seem to activate $\beta$-catenin signaling and lead to its translocation into the nucleus (Chilosi et al., 2003). NUMB may disable the interaction between E-cadherin and $\beta$-catenin and thus contribute to $\beta$-catenin activation, although future studies are required to substantiate such a model.

Inactivation of $N u m b / l$ in mouse lung epithelia did not only prevent fibrosis after bleomycin treatment but also had a clear effect on the generation of normal numbers of ATII cells during development. It seems likely that attenuation of Wnt$\beta$-catenin signaling due to the absence of NUMB is the main cause for reduced ATII cell formation, since the Wnt- $\beta$-catenin pathway plays a pivotal role for ATII cell expansion during lung alveologenesis and maturation (Frank et al., 2016). The reduced numbers of ATII cells may also contribute to the protection against fibrosis by diminishing release of pro-fibrotic factors from fewer ATII cells or by other reasons. Finally, NUMB may exert additional functions in ATII cells, which might play a role for survival under bleomycin treatment, since the dramatic improvement in survival of $N u m b / l$ cdKO animal was more pronounced than expected from the reduction in fibrosis. Such mechanisms might synergize with the blunted activation of the $\beta$-catenin signaling in $\mathrm{Numb} / \mathrm{l} \mathrm{cdKO}$ mice.

\section{CONCLUSION}

In conclusion, we demonstrate that $N u m b / l$ play a critical role for allowing regular expansion of ATII cells during lung development and for promoting lung fibrosis. Our data indicate that $N u m b / l$ are required for the activation of $\beta$-catenin signaling in lung epithelial cells following injury, probably by stimulating CK2, thereby leading to stabilization and enhanced transcriptional activation of $\beta$-catenin. We assume that pharmacological approaches targeting the $\mathrm{NUMB} / \mathrm{CK} 2 / \beta$-catenin axis represent a promising strategy to develop innovative therapies for the treatment of PF.

\section{DATA AVAILABILITY STATEMENT}

The raw data supporting the conclusions of this article will be made available by the authors, without undue reservation.

\section{ETHICS STATEMENT}

The animal study was reviewed and approved by the Regierungspräsidium Darmstadt.

\section{AUTHOR CONTRIBUTIONS}

TB and AS designed all experiments. MH and AI performed the majority of the experiments with the contribution from PK, ST, HA-T, HN, MK, and IS performed data analysiing and interpreted data. AGö and BG provided stable eGFP-NUMB1-4 overexpressing MLE12 cells. TB and AI wrote the manuscript. SP and AGü helped in design the experiments and contributed to writing and editing the manuscript. TB and AS supervised the project. All authors read the manuscript and provided critical comments. 


\section{FUNDING}

This work was supported by the German Research Foundation (DFG) Project-ID 268555672-SFB 1213 (TP B02), the DFG Transregional Collaborative Research Center 81 (TP A02), the DFG Clinical Research Group KFO309 TP08, the Excellence Cluster Cardio-Pulmonary Institute (CPI), the German Center for Cardiovascular Research (DZHK), and the German Center for Lung Research (DLZ).

\section{ACKNOWLEDGMENTS}

We thank M. Euler and U. Eule for technical assistance.

\section{SUPPLEMENTARY MATERIAL}

The Supplementary Material for this article can be found online at: https://www.frontiersin.org/articles/10.3389/fcell.2021. 639162/full\#supplementary-material

\section{REFERENCES}

Adegunsoye, A., and Strek, M. E. (2016). Therapeutic approach to adult fibrotic lung diseases. Chest 150, 1371-1386. doi: 10.1016/j.chest.2016.07.027

Aktary, Z., Bertrand, J. U., and Larue, L. (2016). The WNT-less wonder: WNTindependent beta-catenin signaling. Pigment Cell Melanoma Res. 29, 524-540. doi: $10.1111 / \mathrm{pcmr} .12501$

Al-Tamari, H. M., Dabral, S., Schmall, A., Sarvari, P., Ruppert, C., Paik, J., et al. (2018). FoxO3 an important player in fibrogenesis and therapeutic target for idiopathic pulmonary fibrosis. EMBO Mol. Med. 10, 276-293. doi: 10.15252/ emmm.201606261

Aoyagi-Ikeda, K., Maeno, T., Matsui, H., Ueno, M., Hara, K., Aoki, Y., et al. (2011). Notch induces myofibroblast differentiation of alveolar epithelial cells via transforming growth factor-\{beta\}-Smad3 pathway. Am. J. Respir. Cell Mol. Biol. 45, 136-144. doi: 10.1165/rcmb.2010-0140OC

Ashcroft, T., Simpson, J. M., and Timbrell, V. (1988). Simple method of estimating severity of pulmonary fibrosis on a numerical scale. J. Clin. Pathol. 41, 467-470. doi: $10.1136 /$ jcp.41.4.467

Aumiller, V., Balsara, N., Wilhelm, J., Gunther, A., and Konigshoff, M. (2013). WNT/beta-catenin signaling induces IL-1beta expression by alveolar epithelial cells in pulmonary fibrosis. Am. J. Respir. Cell Mol. Biol. 49, 96-104. doi: 10. 1165/rcmb.2012-0524OC

Baarsma, H. A., and Konigshoff, M. (2017). 'WNT-er is coming': WNT signalling in chronic lung diseases. Thorax 72, 746-759. doi: 10.1136/thoraxjnl-2016209753

Camelo, A., Dunmore, R., Sleeman, M. A., and Clarke, D. L. (2014). The epithelium in idiopathic pulmonary fibrosis: breaking the barrier. Front. Pharmacol. 4:173. doi: $10.3389 /$ fphar.2013.00173

Cao, H., Wang, C., Chen, X., Hou, J., Xiang, Z., Shen, Y., et al. (2018). Inhibition of Wnt/beta-catenin signaling suppresses myofibroblast differentiation of lung resident mesenchymal stem cells and pulmonary fibrosis. Sci. Rep. 8:13644. doi: 10.1038/s41598-018-28968-9

Chen, X., Shi, C., Meng, X., Zhang, K., Li, X., Wang, C., et al. (2016). Inhibition of Wnt/beta-catenin signaling suppresses bleomycin-induced pulmonary fibrosis by attenuating the expression of TGF-betal and FGF-2. Exp. Mol. Pathol. 101, 22-30. doi: 10.1016/j.yexmp.2016.04.003

Chilosi, M., Poletti, V., Zamo, A., Lestani, M., Montagna, L., Piccoli, P., et al. (2003). Aberrant Wnt/beta-catenin pathway activation in idiopathic pulmonary fibrosis. Am. J. Pathol. 162, 1495-1502. doi: 10.1016/s0002-9440(10)64282-4
Supplementary Figure 1 | Characterization of Numb/l cdKO animals. (A) RT-qPCR analysis of Numb (left) and Numblike (right) expression in whole-lung homogenates from WT and Numb/l cdKO animals. Histograms show the average $\pm \mathrm{SD}$ of relative mRNA expression of three different mice for each group ( $n=3$; ${ }^{*} p<0.05$; NS, not significant). (B) Lung epithelial cells were isolated from control and Numb/l cdKO animals and subjected to FACS sorting for isolation of EYFP-positive cells. Wild-type mice (Rosa26-EYFP-/-) were used as a negative control. Dead cells were identified by DAPI staining (P1). Viable cells (outside of P1) were analyzed for YFP fluorescence (fluorescein; FITC) to establish the gates for $\mathrm{YFP}^{+}$-positive cells. A representative experiment is shown. (C) Immunofluorescence staining for NUMB (green) and E-cadherin (red) on lung cryosections from control and Numb/l cdKO E16.5 embryos. Note the co-localization of NUMB with the epithelial marker E-cadherin and its specific depletion in Numb/l cdKO mice $(n=3$; scale bar $=15 \mu \mathrm{m})$.

Supplementary Figure 2 | NUMB interacts with cortactin. (A) Gene ontology (GO) enrichment analysis of potential NUMB interactor partners. (B) IF staining for GFP and cortactin of stable NUMB-eGFP-overexpressing cells. Nuclei were counterstained with DAPI (scale bar $=12 \mu \mathrm{m}$ ). (C) IF staining for cortactin of stable scramble (Scr. shRNA) and Numb KD cells (Numb shRNA). Nuclei were counterstained with DAPI (scale bar $=12 \mu \mathrm{m}$ ). (D) Quantification of CK2 $\alpha$ and $\beta$ levels relative to $\mathrm{GAPDH} \pm \mathrm{SD}$ in inputs of the co-immunoprecipitation experiments shown in Figures 4D,E ( $n=5$; ${ }^{*} p<0.05$; NS, not significant).

Supplementary Table 1 | List of NUMB interaction partners. Excel list containing all potential interaction partners of NUMB, as detected by mass spectrometry analysis of co-IPs of eGFP-tagged NUMB in MLE12 cells.

Clevers, H. (2006). Wnt/beta-catenin signaling in development and disease. Cell 127, 469-480. doi: 10.1016/j.cell.2006.10.018

Demedts, M., Behr, J., Buhl, R., Costabel, U., Dekhuijzen, R., Jansen, H. M., et al. (2005). High-dose acetylcysteine in idiopathic pulmonary fibrosis. N. Engl. J. Med. 353, 2229-2242. doi: 10.1056/NEJMoa042976

Dho, S. E., French, M. B., Woods, S. A., and McGlade, C. J. (1999). Characterization of four mammalian numb protein isoforms. Identification of cytoplasmic and membrane-associated variants of the phosphotyrosine binding domain. J. Biol. Chem. 274, 33097-33104. doi: 10.1074/jbc.274.46.33097

Ding, X., Ma, M., Teng, J., Shao, F., Teng, R. K., Zhou, S., et al. (2015). Numb induces e-cadherin adhesion dissolution, cytoskeleton reorganization, and migration in tubular epithelial cells contributing to renal fibrosis. Curr. Mol. Med. 15, 368-379. doi: 10.2174/1566524015666150505162015

Distler, O., Highland, K. B., Gahlemann, M., Azuma, A., Fischer, A., Mayes, M. D., et al. (2019). Nintedanib for systemic sclerosis-associated interstitial lung disease. N. Engl. J. Med. 380, 2518-2528. doi: 10.1056/NEJMoa1903076

Driscoll, B., Kikuchi, A., Lau, A. N., Lee, J., Reddy, R., Jesudason, E., et al. (2012). Isolation and characterization of distal lung progenitor cells. Methods Mol. Biol. 879, 109-122. doi: 10.1007/978-1-61779-815-3_7

Flaherty, K. R., Wells, A. U., Cottin, V., Devaraj, A., Walsh, S. L. F., Inoue, Y., et al. (2019). Nintedanib in progressive fibrosing interstitial lung diseases. N. Engl. J. Med. 381, 1718-1727. doi: 10.1056/NEJMoa1908681

Frank, D. B., Peng, T., Zepp, J. A., Snitow, M., Vincent, T. L., Penkala, I. J., et al. (2016). Emergence of a wave of wnt signaling that regulates lung alveologenesis by controlling epithelial self-renewal and differentiation. Cell Rep. 17, 23122325. doi: 10.1016/j.celrep.2016.11.001

Gao, Y., and Wang, H. Y. (2006). Casein kinase 2 Is activated and essential for Wnt/beta-catenin signaling. J. Biol. Chem. 281, 18394-18400. doi: 10.1074/jbc. M601112200

Gorgens, A., Ludwig, A. K., Mollmann, M., Krawczyk, A., Durig, J., Hanenberg, H., et al. (2014). Multipotent hematopoietic progenitors divide asymmetrically to create progenitors of the lymphomyeloid and erythromyeloid lineages. Stem Cell Rep. 3, 1058-1072. doi: 10.1016/j.stemcr.2014.09.016

Gulino, A., Di Marcotullio, L., and Screpanti, I. (2010). The multiple functions of Numb. Exp. Cell Res. 316, 900-906. doi: 10.1016/j.yexcr.2009.11.017

Harris, T. J., and Tepass, U. (2010). Adherens junctions: from molecules to morphogenesis. Nat. Rev. Mol. Cell Biol. 11, 502-514. doi: 10.1038/nrm2927

Hayward, P., Brennan, K., Sanders, P., Balayo, T., DasGupta, R., Perrimon, N., et al. (2005). Notch modulates Wnt signalling by associating with 
Armadillo/beta-catenin and regulating its transcriptional activity. Development 132, 1819-1830. doi: 10.1242/dev.01724

Hill, C., Jones, M. G., Davies, D. E., and Wang, Y. (2019). Epithelial-mesenchymal transition contributes to pulmonary fibrosis via aberrant epithelial/fibroblastic cross-talk. J. Lung Health Dis. 3, 31-35.

Hu, X. B., Ouyang, L. Z., He, Y., and Xia, M. Z. (2019). Numb confers to inhibit epithelial mesenchymal transition via beta-catenin/Lin28 signaling pathway in breast cancer. Exp. Mol. Pathol. 109:104262. doi: 10.1016/j.yexmp.2019.10 4262

Huang, J., Chen, Z., Li, J., Chen, Q., Li, J., Gong, W., et al. (2017). Protein kinase CK2alpha catalytic subunit ameliorates diabetic renal inflammatory fibrosis via NF-kappaB signaling pathway. Biochem. Pharmacol. 132, 102-117. doi: 10.1016/j.bcp.2017.02.016

Hulsken, J., Birchmeier, W., and Behrens, J. (1994). E-cadherin and APC compete for the interaction with beta-catenin and the cytoskeleton. J. Cell Biol. 127(6Pt 2), 2061-2069. doi: 10.1083/jcb.127.6.2061

Ianni, A., Hoelper, S., Krueger, M., Braun, T., and Bober, E. (2017). Sirt7 stabilizes rDNA heterochromatin through recruitment of DNMT1 and Sirt1. Biochem. Biophys. Res. Commun. 492, 434-440. doi: 10.1016/j.bbrc.2017.08.081

Ianni, A., Kumari, P., Tarighi, S., Simonet, N. G., Popescu, D., Guenther, S., et al. (2021). SIRT7-dependent deacetylation of NPM promotes p53 stabilization following UV-induced genotoxic stress. Proc. Natl. Acad. Sci. U.S.A. 118:e2015339118. doi: 10.1073/pnas.2015339118

Ishiguro, H., Okubo, T., Kuwabara, Y., Kimura, M., Mitsui, A., Sugito, N., et al. (2017). NOTCH1 activates the Wnt/beta-catenin signaling pathway in colon cancer. Oncotarget 8, 60378-60389. doi: 10.18632/oncotarget.19534

Jansing, N. L., McClendon, J., Henson, P. M., Tuder, R. M., Hyde, D. M., and Zemans, R. L. (2017). Unbiased quantitation of alveolar Type II to alveolar Type I cell transdifferentiation during repair after lung injury in mice. Am. J. Respir. Cell Mol. Biol. 57, 519-526. doi: 10.1165/rcmb.2017-0037MA

Katzen, J., and Beers, M. F. (2020). Contributions of alveolar epithelial cell quality control to pulmonary fibrosis. J. Clin. Invest. 130, 5088-5099. doi: 10.1172/ JCI139519

Kim, K. K., Kugler, M. C., Wolters, P. J., Robillard, L., Galvez, M. G., Brumwell, A. N., et al. (2006). Alveolar epithelial cell mesenchymal transition develops in vivo during pulmonary fibrosis and is regulated by the extracellular matrix. Proc. Natl. Acad. Sci. U.S.A. 103, 13180-13185. doi: 10.1073/pnas.0605669103

Konigshoff, M., Balsara, N., Pfaff, E. M., Kramer, M., Chrobak, I., Seeger, W., et al. (2008). Functional Wnt signaling is increased in idiopathic pulmonary fibrosis. PLoS One 3:e2142. doi: 10.1371/journal.pone.0002142

Konigshoff, M., Kramer, M., Balsara, N., Wilhelm, J., Amarie, O. V., Jahn, A., et al. (2009). WNT1-inducible signaling protein-1 mediates pulmonary fibrosis in mice and is upregulated in humans with idiopathic pulmonary fibrosis. J. Clin. Invest. 119, 772-787. doi: 10.1172/JCI33950

Korfei, M., Stelmaszek, D., MacKenzie, B., Skwarna, S., Chillappagari, S., Bach, A. C., et al. (2018). Comparison of the antifibrotic effects of the panhistone deacetylase-inhibitor panobinostat versus the IPF-drug pirfenidone in fibroblasts from patients with idiopathic pulmonary fibrosis. PLoS One 13:e0207915. doi: 10.1371/journal.pone.0207915

Kulkarni, T., de Andrade, J., Zhou, Y., Luckhardt, T., and Thannickal, V. J. (2016). Alveolar epithelial disintegrity in pulmonary fibrosis. Am. J. Physiol. Lung Cell. Mol. Physiol. 311, L185-L191. doi: 10.1152/ajplung.00115.2016

Kuo, C. T., Mirzadeh, Z., Soriano-Navarro, M., Rasin, M., Wang, D., Shen, J., et al. (2006). Postnatal deletion of Numb/Numblike reveals repair and remodeling capacity in the subventricular neurogenic niche. Cell 127, 1253-1264. doi: 10. 1016/j.cell.2006.10.041

Kwon, C., Cheng, P., King, I. N., Andersen, P., Shenje, L., Nigam, V., et al. (2011). Notch post-translationally regulates beta-catenin protein in stem and progenitor cells. Nat. Cell Biol. 13, 1244-1251. doi: 10.1038/ncb2313

Lam, A. P., Flozak, A. S., Russell, S., Wei, J., Jain, M., Mutlu, G. M., et al. (2011). Nuclear beta-catenin is increased in systemic sclerosis pulmonary fibrosis and promotes lung fibroblast migration and proliferation. Am. J. Respir. Cell Mol. Biol. 45, 915-922. doi: 10.1165/rcmb.2010-0113OC

Li, W., Wu, J., Yang, J., Sun, S., Chai, R., Chen, Z. Y., et al. (2015). Notch inhibition induces mitotically generated hair cells in mammalian cochleae via activating the Wnt pathway. Proc. Natl. Acad. Sci. U.S.A. 112, 166-171. doi: 10.1073/pnas. 1415901112
Liang, J., Han, B., Zhang, Y., and Yue, Q. (2019). Numb inhibits cell proliferation, invasion, and epithelial-mesenchymal transition through PAK1/beta-catenin signaling pathway in ovarian cancer. Onco Targets Ther. 12, 3223-3233. doi: 10.2147/OTT.S194725

Liu, G., Wang, Y., Yang, L., Zou, B., Gao, S., Song, Z., et al. (2019). Tetraspanin 1 as a mediator of fibrosis inhibits EMT process and Smad2/3 and beta-catenin pathway in human pulmonary fibrosis. J. Cell. Mol. Med. 23, 3583-3596. doi: $10.1111 / \mathrm{jcmm} .14258$

Livak, K. J., and Schmittgen, T. D. (2001). Analysis of relative gene expression data using real-time quantitative PCR and the 2(-Delta Delta C(T)) Method. Methods 25, 402-408. doi: 10.1006/meth.2001.1262

Luo, Z., Mu, L., Zheng, Y., Shen, W., Li, J., Xu, L., et al. (2020). NUMB enhances Notch signaling by repressing ubiquitination of NOTCH1 intracellular domain. J. Mol. Cell Biol. 12, 345-358. doi: 10.1093/jmcb/mjz088

Magnini, D., Montemurro, G., Iovene, B., Tagliaboschi, L., Gerardi, R. E., Lo Greco, E., et al. (2017). Idiopathic pulmonary fibrosis: molecular endotypes of fibrosis stratifying existing and emerging therapies. Respiration 93, 379-395. doi: $10.1159 / 000475780$

Maher, T. M., Corte, T. J., Fischer, A., Kreuter, M., Lederer, D. J., MolinaMolina, M., et al. (2018). Pirfenidone in patients with unclassifiable progressive fibrosing interstitial lung disease: design of a double-blind, randomised, placebo-controlled phase II trial. BMJ Open Respir. Res. 5:e000289. doi: 10.1136/ bmiresp-2018-000289

McGill, M. A., and McGlade, C. J. (2003). Mammalian numb proteins promote Notch1 receptor ubiquitination and degradation of the Notch1 intracellular domain. J. Biol. Chem. 278, 23196-23203. doi: 10.1074/jbc.M30282 7200

McGill, M. A., Dho, S. E., Weinmaster, G., and McGlade, C. J. (2009). Numb regulates post-endocytic trafficking and degradation of Notchl. J. Biol. Chem. 284, 26427-26438. doi: 10.1074/jbc.M109.014845

Mutze, K., Vierkotten, S., Milosevic, J., Eickelberg, O., and Konigshoff, M. (2015). Enolase 1 (ENO1) and protein disulfide-isomerase associated 3 (PDIA3) regulate Wnt/beta-catenin-driven trans-differentiation of murine alveolar epithelial cells. Dis. Model. Mech. 8, 877-890. doi: 10.1242/dmm.019117

Parimon, T., Yao, C., Stripp, B. R., Noble, P. W., and Chen, P. (2020). Alveolar epithelial Type II cells as drivers of lung fibrosis in idiopathic pulmonary fibrosis. Int. J. Mol. Sci. 21:2269. doi: 10.3390/ijms21072269

Perl, A. K., Tichelaar, J. W., and Whitsett, J. A. (2002). Conditional gene expression in the respiratory epithelium of the mouse. Transgenic Res. 11, 21-29. doi: 10.1023/a:1013986627504

Petersen, P. H., Zou, K., Hwang, J. K., Jan, Y. N., and Zhong, W. (2002). Progenitor cell maintenance requires numb and numblike during mouse neurogenesis. Nature 419,929-934. doi: 10.1038/nature01124

Petersen, P. H., Zou, K., Krauss, S., and Zhong, W. (2004). Continuing role for mouse Numb and Numbl in maintaining progenitor cells during cortical neurogenesis. Nat. Neurosci. 7, 803-811. doi: 10.1038/nn1289

Ponce, D. P., Maturana, J. L., Cabello, P., Yefi, R., Niechi, I., Silva, E., et al. (2011). Phosphorylation of AKT/PKB by CK2 is necessary for the AKT-dependent up-regulation of beta-catenin transcriptional activity. J. Cell. Physiol. 226, 1953-1959. doi: 10.1002/jcp.22527

Raghu, G., Remy-Jardin, M., Myers, J. L., Richeldi, L., Ryerson, C. J., Lederer, D. J., et al. (2018). Diagnosis of idiopathic pulmonary fibrosis. An official ATS/ERS/JRS/ALAT clinical practice guideline. Am. J. Respir. Crit. Care Med. 198:e44-e68. doi: 10.1164/rccm.201807-1255ST

Rasin, M. R., Gazula, V. R., Breunig, J. J., Kwan, K. Y., Johnson, M. B., Liu-Chen, S., et al. (2007). Numb and Numbl are required for maintenance of cadherinbased adhesion and polarity of neural progenitors. Nat. Neurosci. 10, 819-827. doi: $10.1038 / \mathrm{nn} 1924$

Rock, J. R., Barkauskas, C. E., Cronce, M. J., Xue, Y., Harris, J. R., Liang, J., et al. (2011). Multiple stromal populations contribute to pulmonary fibrosis without evidence for epithelial to mesenchymal transition. Proc. Natl. Acad. Sci. U.S.A. 108, E1475-E1483. doi: 10.1073/pnas.1117988108

Selman, M., and Pardo, A. (2012). Alveolar epithelial cell disintegrity and subsequent activation: a key process in pulmonary fibrosis. Am. J. Respir. Crit. Care Med. 186, 119-121. doi: 10.1164/rccm.201206-0997ED

Selman, M., and Pardo, A. (2014). Revealing the pathogenic and aging-related mechanisms of the enigmatic idiopathic pulmonary fibrosis. an integral model. 
Am. J. Respir. Crit. Care Med. 189, 1161-1172. doi: 10.1164/rccm.2013122221PP

Selman, M., Pardo, A., and Kaminski, N. (2008). Idiopathic pulmonary fibrosis: aberrant recapitulation of developmental programs? PLoS Med. 5:e62. doi: 10. 1371/journal.pmed.0050062

Staitieh, B. S., Renzoni, E. A., and Veeraraghavan, S. (2015). Pharmacologic therapies for idiopathic pulmonary fibrosis, past and future. Ann. Med. 47, 100-105. doi: 10.3109/07853890.2014.991751

Tanjore, H., Cheng, D. S., Degryse, A. L., Zoz, D. F., Abdolrasulnia, R., Lawson, W. E., et al. (2011). Alveolar epithelial cells undergo epithelial-to-mesenchymal transition in response to endoplasmic reticulum stress. J. Biol. Chem. 286, 30972-30980. doi: 10.1074/jbc.M110.181164

Tanjore, H., Xu, X. C., Polosukhin, V. V., Degryse, A. L., Li, B., Han, W., et al. (2009). Contribution of epithelial-derived fibroblasts to bleomycin-induced lung fibrosis. Am. J. Respir. Crit. Care Med. 180, 657-665. doi: 10.1164/rccm. 200903-0322OC

Thabut, G., Christie, J. D., Ravaud, P., Castier, Y., Dauriat, G., Jebrak, G., et al. (2009). Survival after bilateral versus single-lung transplantation for idiopathic pulmonary fibrosis. Ann. Intern. Med. 151, 767-774. doi: 10.7326/0003-4819151-11-200912010-00004

Todd, N. W., Luzina, I. G., and Atamas, S. P. (2012). Molecular and cellular mechanisms of pulmonary fibrosis. Fibrogenesis Tissue Repair 5:11. doi: 10. 1186/1755-1536-5-11

Uemura, T., Shepherd, S., Ackerman, L., Jan, L. Y., and Jan, Y. N. (1989). numb, a gene required in determination of cell fate during sensory organ formation in Drosophila embryos. Cell 58, 349-360. doi: 10.1016/0092-8674(89)90 849-0

Verdi, J. M., Bashirullah, A., Goldhawk, D. E., Kubu, C. J., Jamali, M., Meakin, S. O., et al. (1999). Distinct human NUMB isoforms regulate differentiation vs. proliferation in the neuronal lineage. Proc. Natl. Acad. Sci. U.S.A. 96, 10472-10476. doi: 10.1073/pnas.96.18.10472

Wang, S., and Jones, K. A. (2006). CK2 controls the recruitment of Wnt regulators to target genes in vivo. Curr. Biol. 16, 2239-2244. doi: 10.1016/j.cub.2006. 09.034
Wert, S. E., Glasser, S. W., Korfhagen, T. R., and Whitsett, J. A. (1993). Transcriptional elements from the human SP-C gene direct expression in the primordial respiratory epithelium of transgenic mice. Dev. Biol. 156, 426-443. doi: 10.1006/dbio.1993.1090

Wynn, T. A. (2011). Integrating mechanisms of pulmonary fibrosis. J. Exp. Med. 208, 1339-1350. doi: 10.1084/jem.20110551

Zhang, Y., Dees, C., Beyer, C., Lin, N. Y., Distler, A., Zerr, P., et al. (2015). Inhibition of casein kinase II reduces TGFbeta induced fibroblast activation and ameliorates experimental fibrosis. Ann. Rheum. Dis. 74, 936-943. doi: 10.1136/ annrheumdis-2013-204256

Zhang, Z., Qu, J., Zheng, C., Zhang, P., Zhou, W., Cui, W., et al. (2018). Nrf2 antioxidant pathway suppresses Numb-mediated epithelial-mesenchymal transition during pulmonary fibrosis. Cell Death Dis. 9:83. doi: 10.1038/s41419017-0198-x

Zhong, W., Jiang, M. M., Schonemann, M. D., Meneses, J. J., Pedersen, R. A., Jan, L. Y., et al. (2000). Mouse numb is an essential gene involved in cortical neurogenesis. Proc. Natl. Acad. Sci. U.S.A. 97, 6844-6849. doi: 10.1073/pnas.97. 12.6844

Zilian, O., Saner, C., Hagedorn, L., Lee, H. Y., Sauberli, E., Suter, U., et al. (2001). Multiple roles of mouse Numb in tuning developmental cell fates. Curr. Biol. 11, 494-501. doi: 10.1016/s0960-9822(01)00149-x

Conflict of Interest: The authors declare that the research was conducted in the absence of any commercial or financial relationships that could be construed as a potential conflict of interest.

Copyright (c) 2021 Ianni, Hofmann, Kumari, Tarighi, Al-Tamari, Görgens, Giebel, Nolte, Krüger, Salwig, Pullamsetti, Günther, Schneider and Braun. This is an openaccess article distributed under the terms of the Creative Commons Attribution License (CC BY). The use, distribution or reproduction in other forums is permitted, provided the original author(s) and the copyright owner(s) are credited and that the original publication in this journal is cited, in accordance with accepted academic practice. No use, distribution or reproduction is permitted which does not comply with these terms. 